\title{
HISTÓRICO DAS PESQUISAS SOBRE SOLOS ATÉ MEADOS DO SÉCULO XX, COM ÊNFASE NO BRASIL
}

\author{
Carlos Roberto ESPINDOLA
}

\begin{abstract}
RESUMO
Até a primeira metade do século XIX, investigadores consideravam os solos um manto alterado superficial sobre rochas capaz de sustentar plantas. Os países desenvolvidos já detinham avançados conhecimentos de suas geologias, climas, e recursos naturais. O russo V.V. Dokuchaev desenvolveu a concepção da formação de um solo a partir da interação dos fatores ambientais gerando processos internos. Esta evolução era evidenciada pelas diferentes "camadas" formadas - horizontes compondo um perfil de solo. Cada distinta interação dos fatores e processos resultaria um determinado tipo de solo. Surge, assim, uma nova ciência, em 1893 - a Pedologia, que rapidamente se expandiu mundialmente, inclusive em antigas colônias do ultramar. Procurou-se realizar no presente texto um histórico do conhecimento científico dos solos desde o século XVIII até meados do século XX. Nesse longo intervalo, países do terceiro mundo, como o Brasil, contaram inicialmente com investigadores estrangeiros no domínio desses conhecimentos. Aqui a ciência alcançou significativa evolução a partir da segunda metade do século XX, quando foram publicados os primeiros levantamentos de reconhecimento pedológico dos nossos estados federativos.
\end{abstract}

Palavras-chave: Conceitos de solo; História da pedologia; Pedologia tropical.

\section{ABSTRACT}

HISTORY OF THE RESEARCHES OF SOILS TO THE MID-TWENTIETH CENTURY, WITH EMPHASIS ON BRAZIL. By the first half of the 19th century, soil scientists already considered soils as a surficial weathered mantle of rock that sustains vegetation. At that time, more developed countries already had an advanced knowledge of their geology, vegetation and physiographic conditions. The Russian researcher V.V. Dokuchaev developed the concept of soil genesis as resulting from the interaction of environmental factors, and whose evolution can be traced through the different "layers" - horizons - that compose the soil profile. The soil profile, as a structural organization, was recognized as the object of a new science in 1893 - Pedology. It expanded rapidly in developed countries and in former tropical colonies till the middle of the $20^{\text {th }}$ century, as documented here. In former colonies, such as Brazil, the application of this knowledge was initiated with the collaboration of many foreign researchers. Since then, Brazilian soil science has developed significantly, especially since 1958-1960, when the first state soil surveys were published throughout the country.

Keywords: Soil concepts; History of pedology; Tropical pedology.

\section{INTRODUÇÃO}

Solos sempre constituíram objeto de múltiplos interesses, incluindo os de ordem mística como uma das forças da natureza, mas principal- mente como um recurso natural para a produção de alimentos, contabilizados com diferentes valores em conformidade com suas capacidades produtivas, tal como considerado nas tributações impostas aos proprietários de terras. 
Os solos foram, desde há alguns séculos, pesquisados dentro de ciências clássicas como a Química, Agricultura, Geologia, Geografia e Ciências Naturais; os estudos de solos no âmbito da Agronomia estavam inseridos nestas ciências desde o século XVIII, sem uma sistematização que pudessem distinguí-los como uma ciência específica. Em alemão, por exemplo, usava-se o termo bodenkunde significando "estudo do solo", sem uma personalização específica.

No final do século XIX surgiu um termo para designá-la e desenvolvê-la de maneira mais autônoma - Pedologia, fortemente embasada inicialmente em conhecimentos sobre as formações geológicas e, posteriormente, levando em conta climas, relevos e agentes biológicos (aí incluídas as coberturas vegetais e organismos), que se interagiam, propiciando um manto de alteração da litosfera.

Os países desenvolvidos já detinham, naquela época, conhecimentos avançados de seus territórios, no que tange às ciências básicas, e já produziam matérias importantes sobre solos, notadamente para as atividades agrícolas, sobretudo quanto à produtividade de suas terras. A Pedologia veio reforçar a importância de uma sistematização nos estudos de caracterização dos solos, a ponto de individualizá-los.

De qualquer forma, os estudos que antecederam a criação da referida ciência serviram de embasamento para seu desenvolvimento e expansão no mundo. O resgate dos primórdios da Pedologia, objeto dessa contribuição, não pôde prescindir de uma incursão aos conhecimentos clássicos que envolvem a história dos solos, até que a Pedologia tenha se inserido e firmado como um poderoso veículo a justificar uma Ciência do Solo.

Resgates históricos dessa natureza têm sido veiculados pela FAO (Food and Agriculture Organization on the United Nations), ISRIC (International Soil Reference and Information Centre), IUSS (International Union os Soil Sciences) e outros órgãos internacionais em publicações especializadas, impressas e em meio eletrônico. Alguns pesquisadores de diferentes países se notabilizaram nessa tarefa, tais como: LEBARON et al. (1973a, b), KRUPENIKOV (1992), BOULAINE (1994, 1997), TANDARICH et al. (2002), BOCKHEIM et al. (2005), FELLER et al. (2006), YAALON (2008) e HARTEMINK (2010), entre muitos outros.

No Brasil, não obstante sua atual volumosa e densa produção científica sobre os solos, que, segundo BAVEYE et al. (2010), chega a cotejar com a de países de tradição reconhecida, essa proporção é reduzida, talvez pela nossa relativa juventude em termos históricos. Incursões dessa natureza encontram-se, por exemplo, em MONIZ (1982), ESPINDOLA (1992, 2007, 2008, 2016), SCHAEFER et al. (1997) e CAMARGO et al. (2010).

Particularizando as atividades desenvolvidas pela SBCS - Sociedade Brasileira de Ciência do Solo, que em 2017 comemorou seus 70 anos de existência, o eminente pedólogo Luiz Bezerra de Oliveira traçou "Um olhar sobre sua história" (OLIVEIRA 2007), obra que resgata as ações e pesquisas realizadas pela SBCS, também enaltecidas anteriormente por MUGGLER et al. (2013).

No presente texto foram efetuadas incursões bibliográficas sobre a ciência dos solos precedente ao nascimento da Pedologia, a justificar a criação de um campo científico específico para investigar aquele singular corpo tridimensional das paisagens. Seus ditames prenunciavam uma notável expansão dos conhecimentos em escala mundial, ao serem estabelecidos critérios objetivos a possibilitarem analogias e correlações dentro das diversidades das inúmeras nações. O resgate bibliográfico teve que se restringir, entretanto, até o início dos anos 1960 , quando se avolumam internacionalmente as matérias pertinentes, inclusive no Brasil.

\section{ANTIGOS REGISTROS SOBRE OS SOLOS AGRÍCOLAS}

Menções a solos são encontradas até mesmo em civilizações já extintas, como relata MARR (2015), formado pela Universidade de Cambridge, em "Uma história do mundo". Roteirista e apresentador de documentários para rádio e televisão BBC London, ele menciona povos anteriores a 50 mil anos, os quais teriam derrubado florestas para a prática da agricultura em áreas de terras por vezes inundadas, mas de solos muito produtivos.

GONG (1989) menciona um livro chinês de Yugong, há 2.500 anos, em que solos eram diferenciados pelas cores, texturas e hidrologia. Por sua vez, o Conde de Buffon (1707-1788) descreveu um solo ferruginoso rico em minerais secundários e grânulos esféricos de óxidos de ferro e manganês, exibindo as camadas orgânica, organomineral e mineral, destacando o mould como um componente escuro assemelhado a uma terra vegetal, rico em material orgânico (FELLER et al. 2003, 2006). 
Atribui-se a Lomonosov, em 1763, o conceito de solo como um corpo geobiológico formado num longo espaço de tempo, com distintas camadas geradas por fatores climáticos e organismos (HARTEMINK 2010). Observa-se nesse conceito alusões aos agentes de formação do solo: clima, organismos e tempo. Lineu (1707-1778) aventou coberturas vegetais distintas nas diferentes terras, $\mathrm{o}$ que levou YARILOV (1910) a considerá-lo um importante divulgador do papel do solo na natureza.

A rocha como fator de formação de solo é citada em inúmeras referências antigas, mas a sua interação com outros fatores do meio levou WILDE (1963) a creditar a Humboldt um título honorífico pelas suas investigações nos Andes em 1789, por ter aludido à possibilidade de se descobrir determinado tipo de solo a partir da caracterização de plantas e rochas associadas.

Por sua vez, os organismos receberam de DARWIN (1838) a devida relevância, ao mostrar a atuação de minhocas no solo de uma escavação romana na produção do mould, reproduzido num corte vertical com camadas denominadas A-B-C-D, não lhe escapando um alinhamento horizontal de fragmentos grosseiros, ao qual JOHNSON (1990) creditou como sendo a primeira menção ao que viria a ser referido como uma stone line no século seguinte. Já consagrado pela sua teoria evolucionista, retornou ao raciocínio dirigido na produção do mould (DARWIN 1881), o que o tornou alvo de críticas irônicas pela comunidade científica, mas cuja publicação rendeu-lhe uma vendagem apenas comparável à da sua obra sobre a evolução das espécies.

DE GASPARIN (1840) considerou o solo uma camada diferenciada da superfície da Terra, cuja natureza petrográfica revelava o "solo ativo" (zona de grande atividade de raízes) e o "solo inerte", observação certamente procedida em clima temperado, pois no tropical chuvoso essa visão poderia ser muito diferenciada, mormente pela espessura.

Em países europeus, de 1810 a 1875, o embate científico sobre o papel do húmus na nutrição de plantas foi intenso (FELLER et al. 2001). O pluricientista francês Hassenfratz (1755-1827) defendia que o carbono das plantas provinha inteiramente de uma fração solúvel do solo (húmus), baseando-se em pesquisas sobre fotossíntese realizada por pesquisadores da sua época, que mostravam a assimilação de $\mathrm{CO}_{2}$ pelas plantas. DE SAUSSURE (1804) provou que porção essencial do carbono provinha do ar atmosférico, e que reduzida porção pudesse provir do húmus, o que moveu o alemão THAËR (1811) a denominar essa ideia como "teoria do húmus", valorizando a gestão orgânica (ganhos e perdas) na fertilidade do solo. Contudo, LIEBIG (1840) desmontou essa teoria ao demonstrar que a nutrição de plantas se dá pelos componentes minerais, via "solução do solo", com o transporte de carbono, oxigênio e hidrogênio pelo ar e pela água, o que passou a ser concebido como "teoria mineral, ou mineralista", que fez muito avançar o conhecimento sobre a nutrição de plantas com o emprego de fertilizantes químicos, a despeito dos enormes benefícios da matéria orgânica coadjuvante.

Nos Estados Unidos, mapeamentos geológicos progrediram celeremente no século XIX, trazendo constantes alusões entre substratos e granulometria dos solos, ou entre os minerais inalterados e os alterados. HITCHCOCK (1838) assinalou a influência das rochas na natureza dos solos, registrando solos arenosos, barrentos, argilosos calcários, terciários e alúvios em Massachussets. HILGARD (1860) relacionou substratos a produções agrícolas, o que representou um agricultural soil survey a destacar solo e subsolo nos mapeamentos.

Um obscuro livro-texto de 1895, de Beletskii, professor russo de Agronomia e Botânica da Escola de Agricultura de Kazan, foi há pouco tempo resgatado por DOBROVOL'SKII \& ROZHKOV (2009), que o consideraram um dos primeiros livros-textos russo a tratar da "Origem dos solos, composição e propriedades: tipos de solos, classificação, potencialidades e mapeamento".

$\mathrm{Na}$ Alemanha, a denominação Bodenkunde tratava generalizadamente do "estudo do solo" na Química, Ciências Naturais e Geologia (HUNDESHAGEN 1830, SPRENGEL 1837), o que motivou FALLOU $(1853,1857)$ a cogitar uma ciência autônoma específica para tratar do assunto. Assim como em vários países, no Brasil, mesmo no século XX, o tema era desenvolvido em Geologia Agrícola, Agrologia, Agrogeologia, Agroecologia, Química Agrícola ou Agricultura Geral (ESPINDOLA 2008, 2010).

\section{A EMERGÊNCIA DE UMA CIÊNCIA DENOMINADA PEDOLOGIA}

Havia um acúmulo de conhecimentos sobre solos nos países onde os ambientes naturais já eram bem estudados, porém necessitava-se de uma ciência específica para tratar do assunto de maneira personalizada. O alemão Friedrich Albert 
Fallou foi o propositor do termo Pedologie, em vez do simples Bodenkunde, para tratar do estudo do solo numa ampla abrangência, coadjuvada pela Química e outros conteúdos ligados às ciências da terra; apropriou-se, para tanto, do radical pedon $=$ solo (FALLOU 1862).

Todavia, sua obra ficou praticamente restrita à língua alemã, a despeito da grandiosidade do seu conteúdo, o que apenas pôde ser mais generalizadamente reconhecido em nível mundial a partir da tardia tradução francesa promovida por FELLER et al. (2008), cuja síntese em português, incluindo seus reflexos na pedologia nacional emergente, foi divulgada em ESPINDOLA (2014).

Com muita propriedade, Fallou defendia que o conhecimento científico do solo ainda não dispunha de uma disciplina especializada para abordála. Os tratados eram compilações de assuntos paralelos que não definiam tipos de solos, tal como nas ciências naturais. Ele empregou um sistema classificatório estreitamente embasado na natureza dos substratos, ainda que admitindo materiais transportados e de recobrimento transformando-se em solos.

Por volta daquela época, grandes avanços na ciência surgiram com a tabela periódica dos elementos químicos, criada pelo russo-siberiano D. I. Mendeleiev (1834-1907), e com a teoria sobre a origem das espécies do inglês Charles Darwin o "evolucionismo", que várias ciências adotaram. Nesse cenário, surge o físico-matemático-geólogo russo V.V. Dokuchaev (1846-1903), formado em 1871 pela Universidade de São Petersburgo, requisitado pelo governo para procurar mitigar a queda da produção agrícola de uma importante zona de exportação, decorrente de uma seca prolongada, o que resultou na organização de uma equipe multidisciplinar com pesquisadores de diversas regiões e países.

O evolucionismo no desenvolvimento do solo foi a tônica apoiada na evidência de camadas distintas superpostas ao substrato (rocha mãe) os horizontes, compondo um perfil volumétrico. Dokuchaev apropriou-se do termo Pedologie de Fallou (Potchovovedenie, em russo) e representou os horizontes por A, B e C, talvez influenciado pelo corte vertical de Darwin ao representar a ação das minhocas. Anunciou os solos como originados da interação de uma rocha-mãe com o clima, relevo e organismos num dado intervalo de tempo, fatores responsáveis por processos como podzolização, solodização, hidromorfização e outros - uma concepção explicitamente genética (DOKUCHAEV
1879). Sua rica produção científica rendeu-lhe o título de "Pai da Pedologia" (YARILOV 1904).

Ao contrapor os dois cientistas, Fallou e Dokuchaev, que assumiram a Pedologia como a ciência autônoma para o estudo sistematizado do solo, RAMANN (1905) advogou que a importância de Fallou ia muito além da limitada proposição daquele termo. Todavia, BLUME (2002) atribui a relativa desconsideração para com a sua obra pela comunidade internacional ao fato de ela não ter oferecido uma concepção genética para a evolução do solo, tendo ficado muito circunscrita à natureza dos substratos geológicos.

\section{INSTITUCIONALIZAÇÃO E CONSAGRAÇÃO DA PEDOLOGIA RUSSA}

Relatos sobre as atividades desenvolvidas pela equipe de Dokuchaev são numerosos e extensos; KOVDA (1984) aponta-o como um dialético, postulando que no solo todos os fenômenos guardam estreitas inter-relações. Há divergências se o seu primeiro trabalho "As origens dos vales fluviais da Rússia Europeia” foi publicado em 1876 ou em 1878 (BOULAINE 1983, KRUPENIKOV 1992). Porém, seu pioneirismo é atribuído à histórica caracterização do Chernozem - a "terra negra" de elevada produtividade agrícola (DOKUCHAEV 1883). Esse denominativo era tanto usado na linguagem coloquial, como na científica de outros países, como Tchernosiomböden, pelo germânico HERMANN (1836).

Em 1892 Dokuchaev tornou-se Diretor do Instituto Agronômico e Florestal de Nova Alexandria na Polônia; no ano seguinte, ele e seu discípulo mais próximo Sibirtsev surpreenderam o mundo científico na Exposição Internacional em Chicago, com uma monumental coleção de 109 monólitos de solos, mapas e documentos sobre seus levantamentos em diversas regiões (DOKUCHAEV \& SIBIRTSEV 1893). O discípulo formalizou a "lei da zonalidade", da qual derivou os solos zonais, intrazonais e azonais (SIBIRTSEV 1895). O estudo sobre os solos russos, apresentado no VII Congresso Geológico Internacional, em São Petersburgo, ocupou 52 páginas dos Anais (SIBIRTSEV 1897).

A dificuldade com a língua russa levou membros ativos e egressos da equipe de trabalho a promoverem traduções difundindo a Pedologia, a exemplo de Loewinsson-Lessing, da Sociedade Belga de Pedologia (DOKUCHAEV 1890/1891). Em 1899 foi lançado o periódico Pochovovedenie, 
ainda em russo, no mesmo ano de criação da primeira cadeira de Pedologia do mundo, em Nova Alexandria, Polônia, entregue a Sibirtsev, que faleceu, entretanto, em 1900, com apenas 39 anos de idade.

Na Exposição Mundial de Paris de 1899, Dokuchaev exibiu um mapa do Hemisfério Norte contendo 11 unidades de solos. Mas o primeiro mapa mundial coube a Glinka, em 1906, com 18 classes de solos ligadas às zonas climáticas da Terra, em escala 1: 80.000.000, quando Dokuchaev já havia falecido (em 1903, com 57 anos), cercado por ceticismos e misticismos agravados pela intensidade dos trabalhos desenvolvidos e de lutas contra a burocracia interferente (HARTEMINK et al. 2013).

Um dos cientistas alemães de prestígio a divulgar a obra russa em sua língua foi $\mathrm{H}$. Stremme, em 1914. VILENSKY (1924) apresentou os grandes tipos de solos russos em alemão e inglês; porém, a difusão de maior alcance deu-se com MARBUT (1927), ao traduzí-la em inglês no I Congresso Internacional de Ciência do Solo em Washington, ocupando mais de 30 páginas dos respectivos Anais.

No século XX, a divulgação da Pedologia soviética expandiu-se nas primeiras décadas, com os trabalhos sobre a gênese e classificação dos solos de GLINKA $(1916,1927)$, POLYNOV (1923), NEUSTRUEV (1927), AFANASIEV (1927), ZAKHAROV (1927), PRASOLOV (1937) e RODE (1947). Destacam-se ainda os trabalhos sobre as ações do clima e outros fatores do meio (GERASIMOV 1933, GERASIMOV \& GLAZOVSKAYA 1960) e sobre a matéria orgânica (TYURIN 1937, KONONOVA \& ALEKSANDROVA 1958). Países vizinhos ampliaram os conteúdos, com as produções do ucraniano SOKOLOVSKY (1935) e do húngaro KOTZMANN (1935).

Diversos participantes da equipe permaneceram nos territórios investigados, continuando a produzir e a divulgar antigas e novas matérias, algumas vertidas para outras línguas; tornou-se clássica, por exemplo, a obra sobre o ciclo geoquímico de intemperismo de POLYNOV (1937). Apenas em 1934 o periódico Soviet Soil Science começou a ser traduzido para o inglês nos Estados Unidos, ampliando o alcance das pesquisas soviéticas.

Outros integrantes da equipe regressaram às suas origens ou rumaram para outros destinos, ajudando a sedimentar a Pedologia nas novas realidades encontradas. A partir de 1914, sobreveio um fluxo imigratório para os Estados Unidos, principalmente de judeus russos como S.A. Waksman, descobridor da estreptomicina, junto ao pedólogo J.S. Joffe, enquanto A. Schatz destacou-se como vitorioso produtor agrícola naquele país.

$\mathrm{O}$ acúmulo de matérias dessa natureza na primeira metade do século XX acabou por desaguar numa inevitável "Ciência do Solo" composta por diversos ramos, em que a Pedologia se inseriu na Gênese e Cartografia. Vários países intensificaram a criação de suas sociedades de Ciência do Solo, a participação nos respectivos conclaves científicos e a produção de periódicos e publicações sob a égide da Ciência do Solo. Não mais se precisou lançar tais assuntos numa Química do Solo, Agrogeologia ou análogos. Um dos grandes méritos da existência da Pedologia, dentro da Ciência do Solo, além da sistematização mencionada, é a possibilidade maior de extensão dos dados a solos de diversas regiões, mediante correlações taxonômicas.

As notáveis descobertas sobre os solos, tratadas em seus diversos ramos, encontram-se bem retratadas e com ilustrações que abrangem até nossas Cataratas do Iguaçu, em "Le sol-une merveille sous nos pieds" (FELLER et al. 2016), que contempla ainda registros históricos de solos em verdadeiras obras de arte produzidas por civilizações primitivas, além das mais conhecidas atuais, expostas em museus e painéis.

\section{IMPLANTAÇÃO E DIFUSÃO MUNDIAL DA PEDOLOGIA}

$\mathrm{O}$ resgate aqui apresentado limita-se a meados do século XX, em razão da volumosa produção científica acumulada a partir dos anos sessenta em vários países. O Comprehensive System do U.S.D.A. (1960) revolucionou conceitos e a taxonomia pedológica mundial (BARIL 1985). Nessa ocasião, começaram a se alastrar no Brasil os primeiros levantamentos de solos dos estados federativos, ainda com denominações populares e termos extraídos da taxonomia americana.

O levantamento bibliográfico sobre a Pedologia foi mais fácil nos países de línguas que adotam o alfabeto latino. Nas línguas de difícil assimilação, como as orientais, isso foi possível a partir de matérias produzidas em antigas possessões de língua ocidental, usualmente divulgadas pelos órgãos-sede, ou efetuadas por especialistas em missões nesses países. Um exemplo, por excelência, é o da Índia, onde o termo "laterita" descrito pelo britânico BUCHANAN (1807), teve uma 
grande contribuição na criação de uma "Pedologia Tropical".

A Ciência do Solo foi, muitas vezes, tomada como sinônimo da Pedologia, tal como revelavam os extintos prestigiosos periódicos belga - Pédologie e francês - Cahiers ORSTOM, Série Pédologie, cuja abrangência excedia à simples distribuição dos solos, gênese, morfologia e classificação - foco da Pedologia. Fertilidade dos solos e técnicas de manejo, por exemplo, seriam temas mais condizentes com Ciência do Solo. No Brasil, o pioneiro livro "Elementos de Pedologia" (MONIZ 1972), avançou bastante nos propósitos da denominação. Nos países hispânicos, Edafología se superimpôs na designação, procurando abarcar relações solo-planta. Contudo, durante muito tempo, diversos órgãos ainda continuaram a empregar Química Agrícola, Agrogeologia, Agrologia ou Geologia Agrícola, a exemplo da "Conferência Internacional Agrogeológica", no ano de 1909, em Budapeste.

Já abordados os primórdios da escola russa, a Pedologia será doravante estendida a outros países, incluindo antigas colônias europeias. Contudo, como há de se verificar, nesses países os registros, em grande parte, trazem informes sobre os solos sem a sistematização da Pedologia, abrangendo dados científicos mais amplos sobre a Ciência do Solo, que incluem, por exemplo, a química do solo (fertilidade e nutrição de plantas), ou o manejo e conservação de solos agrícolas.

Optou-se por agrupar as nações em "Velho Mundo" (Europa, Ásia e África) e "Novo Mundo" (Américas e Oceania), reservando ao Brasil uma abordagem à parte, com o objetivo de detalhar os fatores que tornaram possível a inserção da Pedologia no país, que contou com a colaboração de investigadores estrangeiros, especialistas em ciências naturais, geografia, geologia e agronomia, tal como se deu também com os demais países latino-americanos.

Segundo o Office of the Official Publications of the European Communities, em Luxemburgo, vários países latino-americanos apenas publicaram seus mapas de solos nos anos 1960 e, além disso, destituídos dos respectivos textos explicativos (SELVARADJOU et al. 2005). RICHTER \& BABBAR (1991) e a FAO/UNESCO (1966) detiveram-se em arrolar informes anteriores a esse período, porém muitos dos registros bibliográficos constam incompletos, sendo aqui mantidos, a despeito das tentativas de aprimoramentos adicionais com outras fontes de consulta. Certas instituições oficiais organizam coletâneas de antigos informes sobre os solos de diversas regiões do mundo; no Brasil, com a Embrapa (Empresa Brasileira de Pesquisa Agropecuária), destaca-se o trabalho organizado por NASSAR (1974).

Infelizmente, algumas nações antigas e muito desenvolvidas nas atividades econômicas e sociais nem sempre disponibilizaram aos órgãos internacionais seus estudos sobre solos até os anos 1960. É o caso, por exemplo, da Suíça, muito embora se tenha o conhecimento dos trabalhos de WIEGNER $(1924,1935)$ sobre estrutura dos solos, e da Suécia, com o levantamento de solos sob cultivo de beterraba elaborado por ARRHENIUS (1935).

Procurou-se adotar na explanação a seguir uma ordem alfabética dos países, incluindo os territórios sob seus domínios até a época coberta pelo resgate bibliográfico proposto.

\subsection{Países do velho mundo}

\section{África do Sul}

Por ter sido colonizada muito tempo por europeus, suas influências se fazem presentes na Pedologia, como atestam os trabalhos de MÜLLER (1895) e JURITZ (1898) para a Colônia do Cabo e de GRIMME (1911) para outras regiões. A partir dos estudos das terras vermelhas lateríticas de diabásios (Red Earths) e mapeamentos em Grupos e Subgrupos de solos do território, VAN DER MERWE $(1924,1935,1940)$ tornou-se referência obrigatória na Pedologia mundial. BEATER (1959), por sua vez, caracterizou os solos com cana-de-açúcar da Costa Norte de Natal.

LEWIS (1936) privilegiou estudos geomorfológicos no território, os quais foram intensificados com a chegada do britânico Lester C. King da Nova Zelândia, que se tornou professor na Universidade de Pietermaritzburg (Província de KwaZulu-Natal), e conquistou reconhecimento mundial com o mapeamento das "superfícies de aplainamento". Estas foram utilizadas em datações relativas e, por vezes, com os solos considerados seus correlativos no tempo geológico (KING 1942, 1948).

Alemanha

O handbuch de BLANCK (1930) traz um minucioso resgate bibliográfico dos solos e cita diversas vezes o pioneiro trabalho de FALLOU (1862), criador do termo Pedologia, assim como os de FESCA (1879) e NOWACKI (1885). Inclui o notável suíço MITSCHERLICH (1909), com a 
paradigmática "Lei do Mínimo" ou dos "rendimentos decrescentes", e as lições de STEINER (1924) sobre agricultura biodinâmica. Por sua vez, ATTERBERG (1912) consagra a escala granulométrica internacional para solos e sedimentos e os limites de consistência do solo em diferentes estados de umidade.

KATZER (1903) distinguiu solos eluviais, originados do substrato, dos gerados a partir de materiais transportados. Peculiaridades dos solos tropicais em territórios do ultramar tornaram-se mais conhecidas com WOHLTMANN (1892), RAMANN (1902), PASSARGE (1903), VAGELER (1909) e STREMME (1917). A VAGELER $(1930,1933)$ coube o primeiro livro sobre solos tropicais, editado em alemão e em inglês; o húmus desses solos foi objeto principal de VON GIESECKE (1930).

O primeiro mapa pedológico do continente europeu coube a STREMME (1928), e em escala mundial, a HOLLSTEINS (1930). Os índices Ki e $\mathrm{Kr}$ (relações molares) foram bem explorados por HARRASSOWITZ (1930), tendo sido incluídos em classificações de solos (PALLMANN 1933).

A microscopia óptica em secções delgadas de solos desenvolvida por KUBIENA (1938), que a denominou "Micropedologia", teve especial repercussão na Pedologia mundial. Sua obra original foi reverenciada pela comunidade científica internacional por ocasião dos seus 70 anos de existência (STOOPS 2009). Em sua permanência pós-guerra na Espanha, produziu um primoroso livro ilustrando a aplicação da técnica em inúmeros solos (KUBIENA, 1952, 1953).

A mineralogia sempre foi bem embasada pelos alemães, antecipando-se à notável descoberta dos raios X, por Roentgen, em 1895, cuja técnica interpretativa foi, por isso, denominada "roentgenografia", que evoluiu com inúmeros procedimentos diagnósticos para solos. Merece ainda ser destacado o trabalho de SCHWERTMANN (1959) sobre a caracterização analítica dos sesquióxidos dos solos tropicais.

Bélgica e antigo Congo Belga (República Democrática do Congo)

Egresso da equipe de Dokuchaev, LOEWNSSON-LESSING (1889), um dos fundadores da Sociedade Belga de Pedologia, divulgou um ensaio crítico em francês sobre a cartografia agronômica do mestre russo. Particularidades dos solos da Bélgica foram descritas por PETTERMANN (1899) e MASSART (1908).
Coube a TAVERNIER \& MARÉCHAL (1957) o relato de vestígios de paleossolos terciários em domínios condrusianos, os quais teriam sido desmantelados no Quaternário atual.

Contudo, a escola belga de Pedologia firmou tradição com os estudos sobre os solos tropicais das antigas colônias africanas, a partir de 1935, especialmente do antigo Congo Belga, como o de BAEYENS (1938), que motivou a criação do INEAC - Institut National pour l'Étude Agronomique du Congo Belge. WAEGEMANS (1948) promoveu uma investigação sobre lateritas. Os trabalhos de DE LEENHEER et al. (1952) e de D'HOORE (1954 a, b) sobre lateritas e solos associados tornaram-se internacionalmente clássicos, mostrando a significativa presença de sesquióxidos livres envolvida. Na cartografia pedológica, D'HOORE et al. (1954) empregaram com sucesso as catenas. SYS (1955) ressaltou a importância dos térmitas na gênese dos Latossolos, que foram incorporados ao mapa do continente africano (SYS 1960).

Raoul Dudal, assessor científico da $\mathrm{FAO} /$ UNESCO, desenvolveu o primeiro esboço de um mapa unificado dos solos da Europa e ampliou a divulgação das especificidades dos solos tropicais em um congresso nas ilhas do Pacífico (BRAMÃO \& DUDAL 1958). VAN WAMBEKE (1959) eternizou a relação entre as porcentagens de silte e argila como um índice de intemperismo, ao constatála muito baixa nos Latossolos africanos.

\section{China}

A China é detentora do conhecimento de seus solos agrícolas desde remotos séculos, porém em língua de difícil domínio para cientistas de outros países. Os trabalhos de acesso mais fácil são aqueles apresentados em congressos internacionais de solos.

Algumas publicações anteriores a 1960 são encontradas em inglês, como a nomenclatura de horizontes de solos encharcados (CHU et al. 1938). No VI Congresso Internacional da Ciência do Solo, em Paris, MA (1956) apresentou uma distribuição geográfica dos solos chineses e HWANG et al. (1956) caracterizaram os solos da região de Lushan, centro da China. GRANT (1962) apresentou em um Simpósio de Solos em Hong Kong uma correlação entre os solos chineses e os de grupos mundiais. 


\section{Dinamarca}

Registros bibliográficos de solos da Escandinávia são escassos no período abrangido pela presente pesquisa. GREVE \& BREUNINGMADSEN (2005) relatam um antigo trabalho de ROTHE (1844) sobre classificação de terras baseada na produtividade agrícola, retomado e atualizado por JENSEN $(1914,1944)$, e uma contribuição de MOSBECH (1922) sobre outros solos cultivados.

\section{Espanha}

A menção de OLÁZABAL (1857) sobre uma tese no âmbito da Edafologia premiada no ano anterior, versando sobre solo, clima, cultivo agrário e florestal na Província de Viscaia, despertou o interesse do meio científico nacional, ao enfatizar as relações solo-planta.

No início do século XIX, o antropólogo/ geógrafo Luis de Hoyos Sáinz desenvolveu uma Geologia Agrícola, o que lhe rendeu lugar de honra na ciência espanhola (HOYOS SÁINZ 1908). Sucedendo-o, o naturalista DANTIN CERECEDA (1917) participou da elaboração de um histórico mapa internacional de solos coordenado pelo renomado pesquisador alemão Hermann Stremme (DEL VILLAR 1927).

Destacou-se o Instituto Nacional de Edafología y Agrobiología com a publicação regular dos Anales de Edafología y Agrobiología, com significativa participação de especialistas em físico-química e húmus (ALBAREDA 1935, ALBAREDA et al. 1942) e Edafologia (MELA MELA 1954). Tais estudos estenderam-se à Guiné espanhola com HOYOS DE CASTRO \& RODRIGUEZ (1956).

A esta escola, legaram importantes contribuições os alemães E. Ramann, na Guiné espanhola, e W.L. Kubiena, em seu retiro na Espanha, em programa pós-guerra no Consejo Superior de Investigaciones Científicas de Madri, onde publicou as memoráveis Claves sistemáticas de suelos (KUBIENA 1952), que serviu de base para SANCHEZ CALVO (1958) caracterizar os solos Braulehm das Ilhas Canárias.

França e antigas colônias

RISLER (1884) analisou a distribuição geográfica dos solos franceses no âmbito da Geologia Agrícola. MÜLLER (1897) produziu um denso livro sobre as ações do húmus na vegetação e no solo ainda sem o emprego do termo Pedologia, que coexistiu com a Química Agrícola (DEHÉRAIN 1902) e a Agricultura Geral (DIFFLOTH 1927).

Solos de florestas foram alvo de muitas pesquisas nas primeiras décadas do século XX, especialmente pela Escola de Nancy, junto à Estação Agronômica do Leste (HENRY 1908). Uma importante referência dessa época foi a matéria de LACROIX (1913), com minuciosas análises de lateritas da Guiné e dos produtos de alteração associados. Mas, de fato, a embrionária Pedologia começou a deslanchar como tal com a chegada do imigrante russo AGAFONOFF (1929).

Erhart, do Institut Pédologique de Strasbourg, publicou um "estudo agrológico" em Madagascar (ERHART1926), seguido por um famoso Tratado de Pedologia (ERHART 1935). OUDIN (1937) impulsionou a classificação pedológica e a cartografia pedológica na França, enquanto DEMOLON (1948) publicou uma obra sobre a dinâmica dos solos. Tais iniciativas propiciaram a criação da Association Française pour l'Étude du Sol AFES, em 1932, e o Institut National de Recherche Agronomique - INRA, em 1948. HÉNIN (1948) ganhou destaque na Física do Solo, e formalizou, com colegas, o profil cultural, de amplo emprego até os dias atuais (HÉNIN et al. 1960).

Da Faculté de Sciences de Strasbourg, George Millot notabilizou-se em estudos de alteração de rocha (MILLOT 1949), popularizando o emprego de transformações isovolumétricas em fenômenos de laterização e bauxitização (MILLOT \& BONIFAS 1955). Em Nancy, DUCHAUFOUR (1956) imprimiu uma visão ecológica do solo, em associação com a Estação Agronômica, do Centre Nationale de Recherche Scientifique - CNRS. No INRA-Versailles, Georges Pédro tornou-se personagem obrigatório na Pedologia mundial, com suas pioneiras pesquisas sobre alterações de rochas em laboratório (PÉDRO 1958).

André Cailleux fundou a Revue de Géomorphologie Dynamique, lecionouna Sorbonne e trabalhou algum tempo no Rio de Janeiro; junto a Jean Tricart, ampliou nossa visão dos solos na paisagem, sob o viés da geomorfologia, como será destacado adiante. A expressão "formações superficiais", abarcando substrato, geomorfologia e solos, coube a JOURNAUX \& DEWOLF (1958), do Centre de Géomorphologie do CNRS de Caën, dada a interação indissociável daqueles elementos nas paisagens.

Investigações nas antigas colônias do ultramar nas primeiras décadas do século XX, com especial destaque a AUBERT (1941), que motivou a cria- 
ção do ORSC - Office de la Recherche Scientifique Coloniale em 1943, renomeada em 1960 como ORSTOM - Office de la Recherche Scientifique et Technique Outre-Mer - de prestígio mundial na pesquisa de solos tropicais. Dentre as inúmeras áreas investigadas pelos seus pesquisadores, citam-se: Nigéria (DABIN 1951), Madagascar (SÉGALEN 1956), Guiné (MAIGNIEN 1958), Costa do Marfim (LENEUF 1959), Congo (DELVIGNE 1959) e Marrocos (BRYSSINE 1950).

$\mathrm{Na}$ Indochina, podem ser mencionados os trabalhos de HENRY (1931) sobre as terras vermelhas e negras de basaltos e de GOUROU (1938) sobre a descrição de seus solos e climas. A Tunísia contou com as contribuições de HOVEROU (1960) sobre o conhecimento dos solos do sul do país e de COINTEPAS \& ROEDERER (1961) sobre as culturas em solos irrigados com água salgada.

\section{Grã Bretanha e antigas possessões}

Dentre os registros mais antigos, podem ser mencionados os trabalhos de MORTON (1843), que trata da conexão genética solo-formação geológica e FOREMAN (1907), que se deteve nos solos de Cambridgeshire. Da Irlanda, KILROE (1907) estabeleceu relações entre solos, geologia e clima. No País de Gales, ROBINSON (1916) caracterizou solos paleozoicos, notabilizando-se com o livro sobre a origem, constituição e classificação de solos (ROBINSON 1932). Na Escócia, a determinação do fósforo orgânico total do solo pelo método de SAUNDERS \& WILLIAMS (1955) tornou-se referência no meio científico.

A noção de catena, introduzida por MILNE (1935), representou um marco na concepção da gênese e distribuição dos solos nas paisagens, tendo sido aplicada com sucesso no oeste africano por NYE (1954). OLLIER (1959) destacou-se no campo da geomorfologia, com a sua two-cycle theory, que assinalou a complexidade dos materiais de origem dos solos tropicais envolvidos em gêneses sucessivas. Na física do solo, EMERSON (1954) tornou-se reconhecido pelos estudos de estabilidade dos agregados.

A Malásia, sob domínio britânico por longo período, detinha uma classificação provisória de solos (OWEN 1951) e mapas pedológicos (PANTON 1957, COULTER et al. 1958). A atual República Democrática Socialista do Sri Lanka, denominada Ceilão desde o domínio português (1505-1658), foi incorporada à Índia até 1948 e se tornou possessão britânica até 1972. Coube a JOACHIM $(1935,1955)$ a descrição de seus grupos de solos; a PANABOKE (1959) a caracterização das particularidades da zona seca; a KANDIAH (1952), os levantamentos para projetos de colonização; a MOORMAN \& PANABOKE (1961) o aprimoramento da classificação dos grupos de solos mais importantes do território.

A Serra Leoa (Sierra Leone) situa-se na África Ocidental; seu nome deve-se ao descobridor português Pedro de Sintra no século XV, mantendo-se no domínio britânico desde 1787, até sua independência em 1961. Os primeiros escravos negros da América do Norte de lá provieram, desde 1652. A respeito dos solos, receberam destaque aqueles encharcados para cultivo de arroz (DOYNE \& GLANVILLE 1933), ou dotados de pôlderes (DENT 1947), com condições pedoambientais peculiares, principalmente pelas variações sazonais de $\mathrm{pH}$ e excesso de sulfetos (TOMLINSON 1957, HART 1959).

A Somália situa-se na costa oriental do continente africano conhecido como "Chifre da África". Sua porção norte esteve sob o jugo britânico (região da Somalilândia), onde GLOVER (1950) caracterizou o processo de infiltração de águas pluviais. Faz fronteira com o Quênia, onde foram feitos estudos sobre o uso de microplots para levantamentos de reconhecimento da estimativa de nutrientes (TIOBURY \& CALTON 1950) e de cultivo em solos sob variações do lençol freático (ROBINSON \& EVANS 1959). Destacam-se ainda trabalhos realizados em outros antigos domínios britânicos: sobre nitrogênio no solo na Tanganica (atual Tanzânia) (HAGENZIEKER 1957), caracterização de solo do delta central na Nigéria (DABIN 1951) e micronutrientes na nutrição de plantas na Uganda (CHENERY 1954).

A Índia merece especial destaque na história dos estudos dos solos tropicais, dado o pioneirismo com a investigação sobre as lateritas do britânico BUCHANAN (1807), que deu origem a inúmeras pesquisas sobre este material e solos correlatos. Coube a ROY \& DAS (1952) o estudo sobre as propriedades eletroquímicas de argilas do Black Cotton Soil. Segundo VAN WAMBEKE (1993), desde 1934 o país dispunha de uma Sociedade Indiana de Ciência do Solo. Pesquisadores da própria nação, como VENKATARAMIAH (1934), foram responsáveis pela elaboração de mapas de solos. A contribuição britânica está presente com os estudos de PENDLETON (1940), a respeito da erosão pelo uso das terras e com a elaboração de quatro levantamentos de solos no Gwalior State (PENDLETON 1947). Com a dissolução do impé- 
rio britânico da Índia, em 1947, surgiu o Paquistão, onde se registra um trabalho eminentemente pedológico em sua porção leste, Nanakhi (KARIM \& KHAN 1955).

\section{Holanda e antigas possessões}

A grande expressão dos solos aluviais na singular posição topográfica holandesa foi precocemente abordada por VAN BEMMELEN (1886), com avanços nos estudos de PONS (1948, 1960). Em função dessas peculiaridades, os estudos dos solos orgânicos (BENNEMA 1954, VAN HEUVELEN et al. 1960) sempre ganharam especial destaque. A Estação Experimental de Wageningen notabilizou-se pelo seu vanguardismo investigativo dos solos.

No domínio das colônias ultramarinas, foram instituídos o Royal Tropical Institute em 1935, o Soil Survey Institute em 1945 e a publicação do Bulletin of the Colonial Institute of Amsterdam. EDELMAN (1946) fez estudos em Java e Sumatra - as Índias Orientais holandesas; em Java, KOENINGS (1950) descreveu o perfil Sawah da cidade de Bogor (Java). Desde suas análises de lateritas, MOHR (1909) tornou-se referência no assunto, e junto a Van Baren, na Indonésia, produziram um clássico livro sobre solos tropicais (MOHR \& VAN BAREN 1954). Por sua vez, VAN SCHUYLENBORGH (1957) ocupou-se especificamente com os solos tropicais andesíticos.

Indonésia, Filipinas, Tailândia, Vietnã (Sudeste asiático)

$\mathrm{Na}$ Indonésia, os solos lateríticos foram descritos por VAN DER VOORT (1950), enquanto os mapeamentos pedológicos e a classificação taxonômica dos solos foram o foco de DUDAL (1957). Nas Filipinas, MOHR (1930) expandiu o conhecimento sobre os solos tropicais na Estação Experimental da Universidade; JESUITAS et al. (1961) ocuparam-se do estudo da evapotranspiração dos solos para fins de irrigação. Na Tailândia, que não esteve sujeita à colonização europeia, PENDLETON (1947) publicou um trabalho abordando desde a formação do solo até sua utilização na planície de Bangkok. O Vietnã, após uma milenar vinculação da China, foi colonizada pela França (Indochina francesa) na segunda metade do século XIX. MOORMAN (1959) descreveu as condições pedológicas e genéticas da planície dos Joncs e depois generalizou informes sobre os solos de todo o país (MOORMAN 1961).
Itália

O mapa geológico italiano que balizou o estudo dos solos surgiu após a criação do Reinado da Itália, em 1861 (CALZOLARI 2013). Dados pioneiros sobre a constituição e propriedades dos terrenos agrários couberam a SESTINI (1899), segundo CONSTANTINI \& DAZZI (2013). DE ANGELIS D'OSSAT (1900) desenvolveu a geologia agrícola da província de Roma e FUNARO (1904) elaborou um Manual de química do terreno.

Atribui-se a VINASSA DE REGNY (1904a, b) o emprego pioneiro do termo Pedologia no país ao tratar das "terras rossas", o qual se generalizou em 1924, na IV Conferência Internacional sobre Pedologia, em Roma, ocasião na qual foi fundada a Sociedade Internacional de Ciência do Solo (VAN BAREN et al. 2000). No evento, o geólogo DE ANGELIS D'OSSAT (1924), presidente do comitê organizador do evento, considerou a "fase litológica" o fundamento de uma classificação de solos e a base do primeiro mapa pedológico do país, como observado por CALZOLARI (2013).

Destacam-se ainda estudos e cartas de solos de CONSTANZINI (1908), MORI (1929), PRINCIPI (1943) e MANCINI (1960), além de um guia de campo desenvolvido por COMEL (1937). Tornaram-se famosas as referências sobre as terras rossas italianas de MURGOCI (1910), GORTANI (1913) e GAUDENZI (1934).

\section{Japão}

Na segunda década do século XX o país já contava com uma associação científica voltada à agricultura que se preocupava com o estudo dos solos do ponto de vista da Pedologia (SOCIETY OF AGRICULTURE - JAPAN 1926), como revela SEKI (1930) com a divulgação dessas pesquisas em evento científico internacional. Em geral, as matérias científicas a esse respeito foram produzidas em japonês e traduzidas em inglês na forma de resumos, a exemplo das várias que se seguem, como a do próprio SEKI (1934) sobre solos sialíticos e alíticos.

Após KAMOSHITA (1940) caracterizar os tipos de solos da planície de Tugaru, ele estendeu seu trabalho na elaboração de um mapa geral dos solos japoneses (KAMOSHITA 1955). Já existiam dados disponíveis sobre a mineralogia dos materiais de origem dos solos de derrames vulcânicos (SUDO 1951, KANNO 1959), assim como estudos de pedogênese e classificação de solos sujeitos a 
encharcamentos periódicos (YAMAZAKI 1960). MATSUI (1957) dedicou-se ao estudo dos solos vermelhos bem drenados.

\section{Portugal}

Um antigo estudo analítico dos terrenos, plantas e fertilizantes orgânicos (estrume) de LAPA (1875) encontra-se abordado no conteúdo de Química Agrícola. Os solos foram tratados na Geologia Agrícola por FIGUEIREDO (1908) e na Química Agrícola por SILVA (1926). Somente com SILVA TEIXEIRA (1947) surge, finalmente, um Glossário de Pedologia.

Uma classificação dos solos foi promovida por REBELLO DA SILVA (1907). A descrição de um Chernozém por BRAMÃO (1942) despertou interesse para os estudos de pedogênese e de distribuição geográfica dos solos do país e dos Açores (MACHADO 1945). Esses progressos propiciaram a elaboração de uma carta pioneira de solos de Portugal (BRAMÃO et al. 1949). Ensaios de adubação em solos pardos do Alentejo foi objeto do trabalho de LUCAS \& FREITAS (1958); o acúmulo de ensaios dessa natureza nos "Postos Experimentais" propiciou a MOURÃO (1958) uma análise estatística desses dados. Neste contexto já se tornavam comuns estudos de "famílias de solos", seguindo os princípios da taxonomia pedológica (SILVA 1959).

Os diversos estudos nas colônias ultramarinas pelo Instituto Superior de Agronomia de Lisboa levaram à criação da Junta de Investigações do Ultramar - JIU, detentora do Centro de Estudos de Pedologia Tropical e da Missão de Pedologia de Angola e Moçambique. Surgem, assim, cartas de solos dos diferentes "distritos" desses territórios, como a do angolano Huila (MISSÃO DE PEDOLOGIA DE ANGOLA 1959) e de outras províncias, incluindo São Tomé-Príncipe e a Guiné Portuguesa (BOTELHO DA COSTA \& AZEVEDO 1960).

\subsection{Países do novo mundo}

\section{Argentina}

Não se encontram muitos registros anteriores a 1960 na literatura sobre os solos do país, embora AMEGHINO (1880) tenha se referido à presença de naturalistas do Velho Mundo investigando terrenos dos pampas no século XIX. Na primeira década do século XX, CRAVETTI (1904) descreveu solos da Província de São Luís, e BOLLA \& LAVENIR
(1908), de Formosa. No Censo Agropecuário Nacional de 1908, LAVENIR (1909) fez constar um panorama da "Agrologia" argentina. $\mathrm{Na}$ III Conferência Interamericana de Agricultura, em Caracas, o INSTITUTO DE SUELOS Y AGROTECNÍA (1945) apresentou símbolos cartográficos para levantamentos edafológicos.

ARENA (1945) ocupou-se da cartografia e classificação de terras, FRENGUELLI (1955) dos solos de loess e limos pampeanos, e TERUGGI et al. (1958), da sedimentologia da zona de Mar del Plata-Miramar. BONFILS et al. (1960) noticiaram que desde 1954 os solos já eram reconhecidos como entidades geográficas tridimensionais classificáveis pelas morfologias dos seus perfis, conceito visivelmente pedológico. Pioneiramente, com WALTHER (1940) e PAPADAKIS (1960), estudos "pedológicos" substituíram "edafológicos" quando não estavam envolvidas relações solo-planta.

Austrália, Nova Zelândia, Nova Guiné e Tasmânia (Oceania)

A Oceania é considerada por muitos como o "Continente Novíssimo", por ter sido o último descoberto, englobando a Austrália, Nova Guiné, Nova Zelândia e Tasmânia. Antes do século XX, a extensa Austrália já dispunha de um sólido embasamento geológico-geomorfológico e conhecimento da diversidade dos solos de algumas regiões (BRUNNICH 1900). Isso se intensificou com JENSEN (1914), que motivou a elaboração de um "mapa pedológico tentativo" (PRESCOTT 1930). Este último produziu, posteriormente, uma matéria de grande repercussão científica para a Pedologia tropical, sobre as lateritas e solos correlatos (PRESCOTT \& PENDLETON 1952).

Desde 1941, a CSIRO - Commonwealth Scientific and Industrial Research Organization - pôde contar com experientes profissionais, que habilmente associavam geomorfologia e solos (STEPHENS 1946), o que deve ser considerado um referencial positivo dentro da Pedologia, principalmente para fins de mapeamento. Além disso, seu patamar de excelência foi ampliado com os avanços da micromorfologia alcançados por BREWER $(1956,1960)$ e BREWER \& SLEEMAN (1960).

No ICRISAT - International Crops Research Institute for the Semi-Arid Tropics, o neozelandês SWINDALE (1955) ganhou destaque com sua tese de $\mathrm{PhD}$ (Madison, EUA) sobre a mineralogia de solos do seu país, realizada com a equipe do Dr. Marion L. Jackson, com quem continuou a pesquisar (SWINDALE \& JACKSON 1956). 
Sua obra sobre intemperismo químico de silicatos na gênese dos solos costuma ser referência recorrente (FIELDES \& SWINDALE 1954). Outros notáveis investigadores neozelandeses no cenário internacional foram R.B. Miller e M. Fitzpatrick (MILLER \& FITZPATRICK 1959).

Irônicas e irascíveis críticas foram expressas na inauguração do prestigioso periódico britânico Soils and Fertilizers - What is the use of pedology $\mathrm{e}$ Obituary notice - sobre a real utilidade da Pedologia (IMPERIAL BUREAU OF SOIL SCIENCE 1938, 1940). O pedólogo australiano NORTHCOTE (1954) refutou-as com muita categoria, particularmente sobre a necessidade da taxonomia pedológica nas diversas modalidades de pesquisas em solos (NORTHCOTE 1960).

Da Nova Zelândia, há antigos registros sobre os solos (ASTON 1906, WILD 1919, FARR et al. 1919) e a geomorfologia (SPEIGHT \& WILD 1918, COTTON 1922), muito ampliada com KING (1930). GRANJE \& GIBBS (1948) e CAMPBELL (1950) avançaram nos conhecimentos ligados à erosão dos solos. Podem ser ainda mencionados os trabalhos de BIRREL \& FIELDES (1952) sobre os vastos solos alofânicos derivados dos vulcanismos, a cartografia pedológica de TAYLOR \& FOX (1956), e os estudos do desenvolvimento radicular das coberturas vegetais de ROBINSON \& JACQUES (1958).

A Tasmânia, uma ilha a $240 \mathrm{~km}$ da costa sudeste da Austrália, constitui um de seus estados. Seus solos foram estudados por STEPHENS (1941), DIMMOCK (1957) e LOREDAY (1957), o último com ênfase nos solos derivados de basaltos.

A Nova Guiné, ou Papua Ocidental, forma com o arquipélago malaio o arquipélago indoaustraliano, situado na parte oriental da Indonésia. BEERS (1949) desenvolveu um levantamento de reconhecimento de solos na região de Sorong (oeste de Nova Guiné).

\section{Bolívia}

Dentre as raras publicações localizadas nos anos 1950, pode-se mencionar a de PRITTCHETT \& QUINTANILLA (1952), que relataram técnicas de melhoria nos solos. Na década seguinte, ARCE PEREIRA (1960) avançou nos estudos de capacidade agrológica, incluindo um guia de classificação. Instruções para amostragem de solos para análises laboratoriais foram abordadas por RODRÍGUEZ IRIARTE (1961).

\section{Canadá}

Os mapeamentos pedológicos no Canadá tiveram início com RUHNKE (1926) e ELLIS (1932). Com a instituição do National Soil Survey, criado em 1940, ampliaram-se os levantamentos, cuja taxonomia era baseada essencialmente na norte-americana. Dados complementares aos mapeamentos, obtidos a partir da termometria, foram desenvolvidos por SMITH (1953) e SMITH \& LITTLE (1959). Os Podzols dos climas de invernos rígidos foram objeto de estudo de STOBBE \& WRIGHT (1959). Face a essas condições climáticas, WILNER (1955) caracterizou os efeitos das baixas temperaturas sobre a umidade disponível em solos de Prairies, enquanto LOGSDAIL \& WEBBER (1959) analisaram a ação do gelo na estrutura de certos componentes dos solos.

\section{Chile}

O Ministério da Agricultura chileno reuniu uma equipe de agrônomos, em 1942, para um levantamento agrológico do território, resultando em mapas nas escalas 1: 250.000 e 1: 850.000 (DÍAS 1948, ESPINOSA 1958). A interação com pesquisadores estrangeiros promoveu uma classificação dos Grandes Grupos de Solos do país (ROBERTS \& DIAZ VIAL 1957). Os solos vulcânicos foram alvo das pesquisas de BESOAIN (1958). É importante destacar nos estudos da ciência dos solos chilena a precocidade no emprego da micromorfologia durante os anos de 1950 pelos pesquisadores chilenos MONASTERIO (1958), LAGOS (1958) e MELLA (1958). A técnica foi assimilada com pesquisadores da escola alemã em missão, praticantes da micropedologia de Kubiena, como MATTHEI (1928).

\section{Colômbia}

Pesquisadores estrangeiros muito contribuíram para o conhecimento dos solos colombianos até a metade do século XX, a exemplo do trabalho "Apontamentos Pedológicos" de SCHAUFELBERGER (1944), que na década seguinte, apresentou uma classificação dos solos do país (SCHAUFELBERGER 1955). Durante a década de 1950 a produção científica dos pesquisadores colombianos foi rica, como se constata com algumas de suas publicações: caracterização de um Podzol (BARSHAD \& ROJAS CRUZ 1950), a série de solos de "La Cabrera" (VEGA \& ROJAS CRUZ 1951), solos de savana (ROJAS CRUZ 1952), solos das regiões cafeeiras (GUTIERREZ 
CORTÉS 1951, PARRA 1954), reconhecimento do uso da terra para fins agrícolas (WEST 1954), classificação de solos (DEL LLANO 1958), análise química de solos (GONZÁLEZ 1959).

\section{Costa Rica}

Na metade de século XIX, a Faculdade de Agronomia costa-riquenha promoveu um estudo agrológico do território (GRANT ARIAS \& AVILA SOLÉ 1950). O IICA - Instituto Interamericano de Cooperação para a Agricultura, antigo Instituto Interamericano de Ciências Agrícolas, órgão da Organização dos Estados Americanos (OEA), consolidou diversas ações, com destaque para os levantamentos de reconhecimento de solos (FUSSELL 1951, ROBINSON \& STRIKER 1951). IVES (1951) investigou a intensidade do runoff sobre o comportamento dos atributos dos solos. HANSBERRY (1952) expôs os avanços recentes na química agrícola. PETERSON \& LEWIS (1953) aprimoraram o método para caracterização do uso da terra. Do ponto de vista produtivo, SANDS (1954) focou nas especificidades dos tratos em solos com café e cacau.

\section{Cuba}

\section{A ACADEMÍA DE CIENCIAS DE CUBA} (1961) adota uma classificação de solos eminentemente genética. Um dos trabalhos pioneiros é o de CRAWLEY (1916), que apresentou uma visão geral das terras cubanas. BENNETT (1928) e BENNETT \& ALLISON (1928) apresentaram uma caracterização dos solos de Cuba, divulgada cerca de 30 anos depois, pela FAO (em castelhano).

Ressalta-se ainda as matérias de AMARGOS (1932) sobre classificação de solos, ALBEAR (1941) sobre a relação entre solos e substratos geológicos e CABRERA MESTRE (1945) sobre a produção agrícola associada aos tipos de solos.

\section{Equador}

Dotado da maior biodiversidade do mundo por unidade de área, fez parte do Império Inca até a chegada dos espanhóis em 1526, tornando-se independente apenas em 1830. Encontrou-se apenas um registro antigo, a respeito da fertilidade dos seus solos, com ênfase na importância da renovação do meio (LLANO BUENAVENTURA 1952).

\section{Estados Unidos}

Levantamentos geológicos no final do século XIX já suscitavam algumas considerações entre substratos, atributos dos solos e desenvolvimento de plantas (HILGARD 1860). Essa diretriz incentivou a cartografia pedológica estabelecida por COFFEY (1912) e WHITNEY (1924), com grande destaque na história mundial da Ciência do Solo (AMUNDSON \& YAALON 1995).

LYON \& BUCKMAN (1922) produziram um livro abordando a natureza e propriedade dos solos - A college text of edafology, incluindo elementos de nutrição de plantas, cujo interesse levou a sucessivas reedições no século XX, inclusive com traduções em português.

A versão inglesa de MARBUT (1927) do trabalho do russo Dokuchaev no I Congresso Internacional de Ciência do Solo e de JOFFE (1932), judeu russo naturalizado, foram eficientes veículos de divulgação. O livro Pedology (JOFFE 1936) esmiuçou os processos pedogenéticos, aos quais SIMONSON (1959) deu uma nova roupagem, com ampla difusão mundial.

Os solos dos Estados Unidos foram descritos por MARBUT (1935). KELLOGG (1937) produziu o famoso Soil Survey Manual, enquanto BALDWIN et al. (1938) estabeleceram uma histórica classificação taxonômica. Os Lateritic Soils passaram a ser designados Latosols por KELLOG (1948), embora THORP \& SMITH (1949) ainda os tenham mantido na atualização da classificação de 1938, assim como as ordens de Solos Zonais, Intrazonais e Azonais.

Suíço naturalizado, JENNY (1941) eternizou a formação do solo $(\mathrm{S})$ na expressão: $\mathrm{S}=\mathrm{f}$ (material de origem, clima, relevo, organismos, tempo). Por sua vez, NIKIFOROFF (1949), russo naturalizado, abordou relações até então pouco exploradas nos trabalhos norte-americanos: a interface Pedologia-Geomorfologia.

Com propósitos conservacionistas, BENNETT (1929) denunciou erosões de monta em áreas agriculturadas do país, e que conduziu a uma classificação de terras associada ao sistema de capacidade de uso (NORTON 1939), de repercussão mundial, aprimorada por KLINGEBIEL \& MONTGOMERY (1961). BAVER (1956) produziu uma emblemática obra sobre a Física dos Solos, contemplando uma caracterização criteriosa da estrutura dos solos, preocupação que o acompanhava há quase três décadas (BAVER \& RHOADES 1932). 
O emprego dos raios $\mathrm{X}$ na mineralogia dos solos (HENDRICKS \& FRY 1930) foi associado às análises da fração argila por JACKSON \& SHERMAN (1953), JACKSON (1958) e MEHRA \& JACKSON (1958), de grande importância para os estudos de pedogênese. Na Sedimentologia, a análise da fração areia despontou com KRUMBEIN \& PETTIJOHN (1938), MARSHALL \& HASEMAN (1942) e REASIDE (1959), entre muitos outros, valorizando o emprego da escala granulométrica logarítmica de WENTWORTH (1922), principalmente para estudos de uniformidade dos materiais de origem dos solos. Nas relações pedologia-geomorfologia, RUHE \& DANIELS (1958) instituíram uma sistemática solos-superfícies geomórficas que foi ampliada na década seguinte.

Desde os anos 50, os Estados Unidos buscavam um aprimoramento na classificação dos solos vigente, o que veio a se concretizar com o "Comprehensive System", com contribuições de pedólogos de várias procedências mundiais, que culminou com a emblemática $7^{\mathrm{a}}$ Aproximação (U.S.D.A. 1960).

Para o estado insular do Havaí encontram-se relatos genéricos sobre os solos (MAXWELL 1895), sua distribuição na ilha (WILCOX 1910), sua gênese (KELLEY 1912), bem como especificações para a produção de açúcar (BURGESS 1917). Os solos também foram objeto de investigações mineralógicas por pesquisadores ligados ao Dr. M. L. Jackson (TAMURA et al. 1955). Em Porto Rico, Mar do Caribe, há estudos sobre a relação entre umidade e teores de argila (LUGO-LOPEZ 1951) e sobre a natureza e propriedades dos principais solos de Lajas Valley (LUGO-LOPEZ 1959). ABRUÑA \& SMITH (1953) associaram propriedades dos solos a difentes tipos de argilominerais.

\section{Guatemala}

Assim como para diversos países latino-americanos, o Inter-American Institute for Cooperation on Agriculture (IICA 1951), sediado em Turrialba, promoveu uma eficaz difusão de obras anteriores a 1960. É o caso de um estudo sobre os solos nos Andes guatemaltecos (IICA 1951). SIMMONS (1953) e DIOS CALLE et al. (1957) fizeram o reconhecimento de solos no país e estabeleceram sua distribuição geográfica.

\section{Guianas, Martinica, Belize e Trindade}

Estes territórios foram, durante muito tempo, possessões europeias na porção mais ocidental do globo terrestre, compondo o Novo Mundo na divisão geográfica estabelecida com as Guianas no continente sul-americano, e os demais no Mar do Caribe, região outrora considerada Índias Ocidentais ou Antilhas.

Desde o século XVIII as Guianas foram genericamente concebidas como "terras baixas" (GUISAN 1788), compostas por antigas colônias da Inglaterra (Guiana Inglesa ou Guiana), Guiana Holandesa (Suriname) e Guiana Francesa, no continente sul-americano.

Uma notável contribuição à pedologia tropical emergente deu-se com o trabalho de HARRISON (1910), na Guiana (Inglesa), que atribuiu à crosta de alteração de rochas básicas o caráter de uma laterita primária. HARDY \& FOLLET-SMITH (1931) e DUTHIE (1939) prosseguiram nessa linha investigativa. SIMONSON (1958) desenvolveu um levantamento de reconhecimento da planície costeira da Guiana.

Sobre a Guiana Francesa, relatos genéricos antigos couberam a BAJON (1778) e DE SAINT AMAND (1822); num salto temporal, CHOUBERT (1952) caracterizou a notável sedimentação que ocorria no território. Os trabalhos de cunho pedológico foram iniciados por COLMETDAAGE (1954), ao comparar os solos da Guiana Francesa com os das Guianas vizinhas.

No Suriname (Guiana Holandesa) os registros do século XIX restringiam-se à geologia e aos padrões de vegetação. No século seguinte, SCHOLS \& COHEN (1953) discorreram sobre o karst, COHEN \& VAN DER EYJK (1953) sobre as savanas, e ZONNEVELD (1952) sobre a geomorfologia. Os solos foram objeto de levantamentos de reconhecimento com VERHOOG (1950), BRINKMAN (1959) e VAN DER EYJK (1957). Os minerais pesados de suas areias foram caracterizados por KIEL (1955) e a matéria orgânica da fauna edáfica por JONGERIUS \& SCHELLING (1960).

$\mathrm{Na}$ Martinica, a escola francesa de solos tornou-se uma das mais ativas no conhecimento pedológico do mundo tropical, desde as pesquisas de HAYOT (1881), que apontou nítidas diferenças entre esses solos e os de climas temperados, a ponto de afirmar que tecnologias agrícolas importadas poderiam produzir resultados medíocres (FELLER et al. 2007). Nas Honduras Britânicas (atual Belize), contou-se com a caracterização dos solos de CHARTERS (1941) e HARDY et al. (1935). Em Trindade, a cerca de $10 \mathrm{~km}$ da costa oriental da 
Venezuela, consta um artigo sobre a nutrição mineral de citrus, creditada a DARCEL (1952).

\section{Honduras}

Ainda como possessão (Honduras Britânica), HARDY et al. (1935) descreveram tipos de solos do território. O Inter-American Institute of Agricultural Sciences -IICA menciona estudos de solos na região de Guayna (ROBERTS 1951a) e de Lean Valley (ROBERTS 1951b). Pela FAO/ UNESCO (1969) há menção a um levantamento de reconhecimento exploratório dos solos produzido por SIMMONS (1959), utilizando integralmente os preceitos pedológicos e de classificação taxonômica.

\section{México}

Os levantamentos até 1960 eram essencialmente voltados a projetos de irrigação, como o de MACÍAS (1936), em Hidalgo, e de MÁRQUEZ (1958), em Aguascalientes. Em áreas não irrigadas, há um registro da exploração de terras de PACHARD (1929). A FAO/UNESCO (1966) menciona os estudo de adaptabilidade dos solos para agricultura (WAITZ 1943) e uma introdução ao estudo dos solos por GONZÁLEZ GALLARDO (1949). Em data posterior, BRAMBILA (1960) trata com maior detalhamento os solos mexicanos.

\section{Nicarágua}

País independente da Espanha em 1821, muitos dos aspectos pedológicos foram inicialmente divulgados em inglês pela FAO, a começar com uma descrição dos solos do país por PENDLETON (1945). TAYLOR (1959) elaborou uma classificação ecológica para as terras de Leon-Chinandega, enquanto VALENCIA (1960) avançou nos atributos morfológicos, classificação e uso agrícola dos solos argilosos do país.

\section{Panamá}

Essa república fez parte da Colômbia até 1903, com forte influência dos Estados Unidos, em função do Canal do Panamá, entre o Atlântico e o Pacífico. Por esse motivo, a maioria das matérias foi inicialmente publicada em inglês. STRIKER (1952) descreveu os solos e as paisagens panamenhas; MATHEUS \& GUZMÁN (1955), a produtividade dos Llanos de Coclé; PUJOL (1958), a fertilidade dos solos; MARTINI et al. (1960), os solos florestais.

\section{Paraguai}

São de fama mundial os Llanos Orientales, e especificamente os Llanos paraguaios na classificação de solos e terras do país (TIRADO SULSONA et al. 1954, TIRADO SULSONA 1959). Dados hidrogeológicos, geofísicos e edafológicos, obtidos por FLATHE et al. (1960), com o apoio do Ministerio de Agricultura y Ganadería, foram aplicados na agricultura na região do Chaco Boreal.

\section{Peru}

É um dos países com mais informes sobre os solos nas primeiras décadas do século XX, com detalhes sobre suas gêneses (LISSON 1924), principais tipos (CARRERAS 1929) e particularidades morfológicas (MATTHEI 1944). Um grande destaque é dado aos guanos e às peculiaridades dos solos nas porções tropicais por MURO (1949), o que possibilitou a ROSSI (1953) a elaboração do primeiro mapa de solos do território peruano. Posteriormente, DROSDOFF (1959) produziu trabalhos sobre os solos da porção sul do país.

\section{República Dominicana}

As antigas publicações sobre solos da República Dominicana constam de órgãos de divulgação norte-americanos, produzidas por pesquisadores estrangeiros, como GOLDICH \& BERGQUIST (1947), responsáveis pelos estudos de solos lateríticos da Serra de Bahoruco, e VEALE (1953), que caracterizou solos no território dominicano.

\section{Uruguai}

Nos anos 1940, já dispunha de profissionais qualificados no estudo de solos, assim como órgãos de divulgação. AGUIRRE (1940) discorre sobre o solo e suas propriedades, enfatizando a caracterização dos atributos dos perfis de solo. ASNARES (1945) empregou uma nomenclatura de solos para o Uruguai baseada estritamente no substrato geológico. FYNN (1946) ocupou-se da gênese e taxonomia, enquanto RIEKEN (1959) desenvolveu um sistema de reconhecimento e classificação de solos do país, aprimorado por FYNN et al. (1959) com o detalhamento dos Grandes Grupos de Solos Uruguaios.

\section{Venezuela}

Conforme CASANOVA OLIVA (1991), os levantamentos de solos no país tiveram início 
em 1936. No $4^{\circ}$ Congresso Latinoamericano da Ciência do Solo, em Maracay, o MINISTERIO DE AGRICULTURA Y CRÍA (1972) divulgou extensa bibliografia sobre a edafologia lá praticada. GRUNWALD \& UZKATEGUI (1940) normatizaram instruções para coleta de amostras, que se somaram às de CAMPOS GIRAL (1946). Uma valorização do estudo do solo para as práticas agrícolas foi defendido por OGG (1950), o que também foi incentivado com veemência por KIENER (1954). Em 1955, MACÍAS VILLADA assumiu Edafologia e Ciência do Solo como termos análogos. A complexidade do meio tropical e sua relação com os problemas agrícolas foi salientada por MEDINA (1951). O desenvolvimento evolutivo dos solos foi tratado por MANZANILLA (1958). Coube a ROJAS (1959) a classificação sistemática dos solos da Venezuela. Ao final da década de 50, o país já dispunha de um mapa dos Grandes Grupos de solos, elaborado por WESTIN et al. (1960).

\section{EMBASAMENTO PARA UMA CIÊNCIA PEDOLÓGICA NO BRASIL}

Até boa parte do século XX, a pedologia brasileira prescindiu de um seguro diagnóstico dos recursos naturais, que ainda era precário em grande parte do território. Essa condição foi, de certa forma, preenchida pelo árduo trabalho de valorosos colaboradores estrangeiros, até que os nacionais emergissem, o que, felizmente, ocorreu com certa rapidez e eficácia.

A primeira referência explícita aos nossos "terrenos" consta da histórica carta de Pero Vaz de Caminha à Corte Portuguesa, por ocasião do descobrimento, que enaltece as boas qualidades das terras e alusão a uma infinita fertilidade dos solos, certamente em razão da exuberância causada pela vegetação tropical (RODRIGUES 1987).

Das viagens do geógrafo navegador italiano Américo Vespúcio, a serviço de Portugal e Espanha, há relatos arquivados na Sociedade Geográfica de Paris, que, segundo D'AVEZAC-MACAYA (1857), poderiam suscitar até uma nova história geral da nação. Uma curiosa menção é a Historia naturalis Brasiliae atribuída a Willem Piso, em 1648, disponibilizada pela Fundação Alexandre De Gusmão (FUNAG 2002).

Com respeito aos primeiros registros da agricultura praticada, o lendário aventureiro mercenário alemão Hans Staden, em 1557, relata o cultivo da mandioca; em 1560, o missionário José de Anchieta menciona o algodão, e em 1627, Frei
Vicente Salvador refere-se à criação de gado e engenhos de cana-de-açúcar (ROMERO \& ROMERO 2009). Tais relatos são destituídos de menções a solos, e apenas se referem às diversas modalidades de uso das terras.

No período do jugo holandês (1630-1654) foi instalado o Jardim Botânico em Recife (PE). Na retomada das terras pelos portugueses, outras unidades congêneres foram criadas em Belém, em 1798, e no Rio de Janeiro, em 1808, com a preocupação de D. João VI pela aclimatação do chá das Índias (HARTEMINK et al. 2008). A boa qualidade do solo sempre foi subentendida pela exuberância da vegetação.

A potencialidade das terras brasileiras consta das obras "A viagem pelo Brasil" (SPIX \& MARTIUS 1823), "Viagem mineralógica na Província de São Paulo", de 1827, de José Bonifácio de Andrada e Silva, e da expedição às Províncias de Rio de Janeiro e Minas Gerais (SAINT-HILAIRE 1830). Num diário sem data de Martim Francisco Ribeiro de Andrade, Conselheiro do Governo Imperial, é relatada uma viagem mineralógica por São Paulo (FUNAG 2002).

Após o esgotamento do pau-brasil, desencadeou-se uma desenfreada exploração mineral do subsolo, principalmente na Província das Minas Gerais, intensificada com as Entradas e Bandeiras. Os caminhos do ouro e das pedras preciosas foram devidamente registrados por GARDNER (1846), melhorando o conhecimento do nosso subsolo e de nossas formações superficiais. Em 1859, há registro de um compêndio sobre Geografia Geral e, especificamente, sobre a brasileira, atribuída a Tomás Pompeo de Souza Brasil (BUENO 2002).

Conforme afirma o alemão naturalizado GERBER (1874), as lateritas de Vila Rica (atual Ouro Preto) foram descritas por HERMANN (1869), somando-se ainda às contribuições de Joaquim Manuel de Macedo, em 1873, e de Joaquim José da Silva, em 1878 (GOLDFEDER E CASTRO 2012). Enquanto a seringueira foi intensamente explorada no Norte, a cana-de-açúcar assumiu expressão no Nordeste e motivou a elaboração de um documento de 508 páginas sobre geologia, física, química, botânica e fisiologia vegetal voltada aos solos brasileiros (MARIVAULT 1848). Ressalta-se, no entanto, que o fabrico do açúcar e seus procedimentos já seguissem há muito tempo as antigas recomendações de MELLO (1816).

Wilhelm Ludwig von Eschwege (1777-1855), o Barão de Eschwege, instalou-se no país em 1810, a pedido da coroa portuguesa. Foi considerado fun- 
dador da Geologia Brasileira, segundo MORAES RÊGO (1932), com a obra Pluto Brasiliensis publicada em nossa língua (VON ESCHEWEGE 1941). Por sua vez, foi consagrado Pai da Paleontologia Brasileira o dinamarquês Peter Wilhelm Lund (1801-1880), que aqui aportou em 1832 e permaneceu até falecer. Alexander Von Humboldt (17671835 ) teve seu ingresso aqui impedido, por ocasião da missão na Amazônia venezuelana, em 1800. O suíço Jean Louis Rudolphe Agassiz (1807-1873) percorreu o Rio Amazonas entre 1865 e 1866, discorrendo sobre a grande intensidade da decomposição das nossas rochas (AGASSIZ 1865).

Acumulavam-se, nessa época, anseios por um ensino e preparo de profissionais voltados à agricultura que estava em pleno desenvolvimento, o que tornou muito oportuna a fundação do Imperial Instituto Baiano de Agricultura - IIBA por D. Pedro II, entre São Francisco do Conde e Santo Amaro, no Recôncavo Baiano (ARAÚJO 2006). Em São Bento das Lages, também na Bahia, em 1875, foi criada a Imperial Escola Agrícola da Bahia - IEAB, com o curso iniciado em 1877, para formações alternativas de técnicos de $2^{\circ}$ grau e profissionais de nível superior.

As paisagens brasileiras começaram, então, a ser investigadas mais detalhadamente por esses profissionais, ainda com colaboradores estrangeiros, como ocorreu, por exemplo, no reconhecimento da orla marítima paranaense de Paranaguá até a Bahia, com PISSIS (1842), enquanto DARWIN (1844) assinalou a natureza vulcânica das Ilhas de Fernando de Noronha. Os fatores de formação dos nossos solos foram assim se explicitando - geologia, relevo, clima, cobertura vegetal e ação antrópica.

A diversidade das coberturas vegetais apontava usos e práticas agrícolas também diversificadas nos solos e climas, tal como mostrado por CHEVALIER (1928), com os campos se contrapondo a florestas e savanas. BIROT (1957) e DRESCH (1957) detiveram-se nos distintos relevos. Investigações geológicas ganharam destaque com a Escola de Minas de Ouro Preto, criada em 1876, por solicitação de D. Pedro II a Claude H. Gorceix, que produziu uma histórica matéria (GORCEIX 1890). Essa lendária instituição formou renomados pesquisadores nacionais (BORBA \& COURAT 1975).

Orville Adalbert Derby esteve no Brasil em 1870, depois retornou e permaneceu mais de 40 anos, até a sua morte. Chefiou a antiga Comissão Geográfica e Geológica de São Paulo (1886-1890) e inaugurou o primeiro número do Boletim da Comissão Geográfica e Geológica da Província de São Paulo (DERBY 1889). Em sua primeira visita, foi acompanhado por Charles Frederic Hartt, aluno de Agassiz em Harvard, que aqui se estabeleceu e dirigiu a lendária Comissão Geológica do Império do Brazil. Hartt descreveu, com pioneirismo, a "Terra Preta de Índio" da Amazônia (HARTT 1885).

Assistente de Hartt, John Casper Branner também residiu no Brasil até seu falecimento, legando uma massiva produção científica (BRANNER 1919); insistiu no prolongado tempo de intemperismo das espessas formações superficiais da rodovia São Paulo-Rio de Janeiro, livres das glaciações quaternárias que assolaram o hemisfério Norte, aí explicitando o tempo como fator de formação dos solos (BRANNER 1896).

Os campos de lava da Bacia do Paraná, descritos por BAKER (1923), sempre exerceram fascínio especial pela singular geração das terras roxas a partir de basaltos e diabásios. O território paulista contou ainda com os estudos de Geologia do Petróleo de WASHBURNE (1930), aos quais se juntaram registros primordiais de MORAES RÊGO $(1930,1932)$ sobre a gênese dos nossos solos e, sobretudo, da geomorfologia.

Pierre Deffontaines fundou a Associação de Geógrafos Brasileiros em 1934 e tornou-se professor universitário no antigo Distrito Federal (cidade do Rio de Janeiro), sendo responsável pela primeira compartimentação do relevo paulista (DEFFONTAINES 1935). Inventários sobre os minerais e minérios de substratos paulistas foram dispostos numa planta provisória da porção sul do estado por KNECHT (1935).

O alemão Reinhard Maack peregrinou por outros continentes até aqui se estabelecer por 46 anos, até o falecimento em 1969, em Curitiba, onde ocupou a cátedra de Geografia Física na então Universidade do Paraná. Seu trabalho sobre o desmantelamento das lateritas paranaenses e formação de solos rendeu-lhe uma tese de doutorado em 1948, aprovada na II Reunião Brasileira de Ciência do Solo, em Campinas (MAACK 1950).

Inúmeras contribuições sobre a geologia e, de forma indireta, sobre os solos, surgiram para diversas áreas do Brasil com nossos próprios pesquisadores, ligados às ciências geológicas, ciências da terra ou, genericamente, às ciências naturais, a maioria deles egressos da Escola de Ouro Preto, a exemplo de GUIMARÃES (1933), com sua notável contribuição sobre rochas básicas. 
OLIVEIRA \& LEONARDOS (1949) produziram um mapa dos solos com cafezais do Brasil central e meridional, reproduzido em MARQUES (1950). A Mineralogia/Geologia foi introduzida em cursos de agronomia, contando com a tradução do livro francês de LAPPARENT (1924), com um longo apêndice específico para o Brasil, redigido por DERBY (1924). Por algum tempo, livros nacionais para colégios tratavam de tais conteúdos com adequada desenvoltura, como, por exemplo, os de DÉCOURT (1937) e LIMA E SILVA \& POTSCH (1938).

Os cursos de Geografia e História da Universidade de São Paulo foram viabilizados em 1934, após a visita de uma missão francesa encabeçada por Pierre Monbeig, que lá se tornou professor e pesquisador das paisagens rurais (MONBEIG 1944). Sua tese "Pioneiros e Fazendeiros de São Paulo", defendida na Universidade da Sorbonne em 1949, tornou-se clássica e é republicada periodicamente. Digno de registro também foi a palestra do Professor Alcides Franco, da Escola Nacional de Agronomia, RJ, em aula inaugural do dia 19/03/1936, intitulada "A evolução da ciência do solo" (FRANCO 1936).

A distribuição espacial dos solos em nossas paisagens pôde ser melhor compreendida com as superfícies geomorfológicas estabelecidas por DE MARTONNE (1943) e ampliadas para o Brasil por KING (1956). BARBOSA (1959) estabeleceu um quadro provisório das superfícies de aplainamento e erosão, com as respectivas datações relativas.

A compreensão adequada da distribuição dos solos nas paisagens paulistas não pôde prescindir da contribuição de Fernando Flávio Marques de Almeida, a exemplo dos trabalhos sobre os relevos cuestiformes (ALMEIDA 1951, ALMEIDA \& BARBOSA 1953). O pesquisador e professor francês Francis Ruellan que permaneceu por muitos anos no Rio de Janeiro, descreveu paisagens de Minas Gerais e do Vale do Paraíba, em particular, identificando materiais de origem de solos eluviais (in situ) e transportados (RUELLAN 1943, 1950).

Com sólida e respeitável produção científica no exterior, Jean Tricart interagiu com pesquisadores nacionais em diversos momentos de sua presença no Brasil. Foi coautor de André Cailleux em um trabalho de ampla difusão na Geografia do Quaternário sobre as zonas fitogeográficas e morfoclimáticas (CAILLEUX \& TRICART 1957) e de outro sobre a limitada presença de cascalheiras em nossas formações superficiais (TRICART 1959). A tectônica moderna nos relevos policíclicos e dis- tribuição dos solos foi enfatizada por FREITAS (1951). O conhecimento geomorfológico-paisagístico brasileiro contou com as pesquisas de Aziz Nacib Ab'Sáber desde o final da década de 40, cobrindo vastas porções territoriais (AB'SÁBER 1949). Sua rica produção científica foi devidamente reverenciada por MODENESI-GAUTTIERI $e t$ al. (2010).

Os primeiros conclaves nacionais de Geologia e de Solos coincidiram no ano de 1947, no Rio de Janeiro, já com uma atuante Sociedade Brasileira de Geologia. Nessa ocasião foi fundada a SBCS - Sociedade Brasileira de Ciência do Solo, presidida então por Álvaro Barcelos Fagundes na direção do SNPA - Serviço Nacional de Pesquisas Agronômicas do Ministério da Agricultura, que sediou a Comissão de Solos do C.N.E.P.A.-Comissão Nacional de Ensino e Pesquisas Agronômicas.

\section{A INSTITUIÇÃO DE UMA PEDOLOGIA BRASILEIRA}

Desde tempos remotos, o uso do solo brasileiro pela agricultura clamava por conhecimentos específicos detalhados, quando ainda imperavam práticas de duvidosa credibilidade, muitas delas empregadas sem cunho científico, como as queimadas generalizadas para "limpeza do solo", ou áreas sem capacidade de sustento de determinadas explorações. Imperavam denominações de solos apropriadas do linguajar popularesco, por vezes discordantes de uma região para outra.

Em "Urupês", MONTEIRO LOBATO (1918) menciona "caeté legítimo", "unha-de-vaca" e "caquera" para solos férteis, e MONBEIG (1944) empregou "terras ariscas" para solos arenosos pouco produtivos. Alguns designativos acabaram incorporados na linguagem técnica-científica, como "massapé", "salmourão" e "terra roxa", o que não foi uma exclusividade nossa, ao se deparar com o antigo "Chernozém" europeu, as "Terras Rossas" mediterrânicas e os "Llanos Orientales" sul-americanos, incorporados do vernáculo popular pela ciência pedológica.

A sistematização dos conhecimentos dos solos ocorreu de forma pioneira no Brasil com a publicação do livro "Elementos de Agrologia", de autoria do professor Gustavo d'Utra, da Imperial Escola Agrícola da Bahia, onde se formou em 1880, na 1ª turma (D’UTRA 1897); a Biblioteca da Escola Superior de Agricultura "Luiz de Queiroz" de Piracicaba dispõe de um exemplar dessa obra. $\mathrm{O}$ autor critica matérias europeias que praticamen- 
te ignoram a agricultura tropical, incluindo a do Brasil. A "Agrologia" seria a ciência a ocupar-se dos terrenos cultivados (formações, constituições e propriedades, classificados em grupos por caracteres específicos). O solo arável (superficial) teria constituições argilosas, silicosas, calcáreas ou humíferas, enquanto o subsolo, materiais terrosos e rochosos. Considerando os preceitos da Mineralogia e Geologia Agrícola, rochas feldspáticas dariam origem a argilas e à potassa, e com a perda dos álcalis, feldspatos assumiriam um estado "kaolínico e de argila pura" (ARAÚJO 2006). No âmbito do Instituto Agronômico Paulista, D'utra abordou os solos de São Paulo (D’UTRA 1899).

No minucioso resgate histórico sobre a Escola Agrícola Prática Luiz de Queiroz (atual ESALQ), PERECIN (2004) comenta que em 1911, em São Paulo ocorreu o "Primeiro Congresso de Ensino Agrícola", noticiado pelo Jornal O ESTADO DE SÃO PAULO (1911), com registro digitalizado pela CORNELL UNIVERSITY (2009) e pela CHICAGO UNIVERSITY (2012). Entre as matérias discutidas constavam nas suas grafias originais: "Noções de Agrogeologia" - origem e constituição dos solos, húmus, propriedades physicas e chimicas; classificação da terra arável; os solos em suas relações com o clima e a terra roxa de São Paulo.

O evento fôra convocado pelo Secretário da Agricultura, Comércio e Obras Públicas do Governo Albuquerque Lins (1908-1912), e contou com personalidades de destaque como Luiz Pereira Barreto, Horace Lane, Edmundo Navarro de Andrade e Gustavo d'Utra. Naquela ocasião, Antônio Pádua Salles, Secretário de Governo, reivindicou uma revisão geral no ensino agrícola, de modo a dar atendimento ao crescente desenvolvimento da agroindústria (ALEXANDRE 2007).

Grande avanço no domínio da ciência dos solos foi conquistado pelo pesquisador Theodureto de Camargo, do Instituto Agronômico de Campinas IAC, que na Alemanha trabalhou com Emil Ramann e Paul Vageler. Este último produziu o primeiro livro mundial sobre solos tropicais (VAGELER $1930,1933)$ e veio a se instalar no IAC, onde tornou o laboratório apto a realizar as análises de solo antes executadas em Wageningen (MONIZ 1982). Juntando-se a Theodureto, surgiram os primeiros trabalhos sob a égide da pedologia, com a representação de perfis A-B-C (CAMARGO \& VAGELER 1936, 1937).

Mesmo nessa época, os conhecimentos sobre solos eram tratados em Química Agrícola ou Agrogeologia em vários países - uma "pré-pedologia", segundo SCHAEFER et al. (1997). Agrogeologia designou, por algum tempo, a Seção de Solos do IAC, onde VAGELER (1953) empregava a expressão "levantamento agrogeológico". Ainda se empregavam termos como "massapés" para solos de várias cores com fendilhamentos ao ressecarem, mas que no levantamento agrogeológico paulista de SETZER (1941), representavam aqueles originados das rochas cristalinas menos ácidas, enquanto "salmourões" eram mais arenosos. No Nordeste, OLIVEIRA (1951) empregou o termo massapé salgado para um solo salino, o que revela a multiplicidade de conceitos regionalizados então empregados.

Aos poucos, a Pedologia foi substituindo Agrogeologia, tanto que SETZER (1945) se autorreferia como pedólogo. No Boletim da Superintendência do Café, PAIVA NETTO (1946) publicou "Notas Pedológicas", embora ainda fossem praticados levantamentos agrológicos (COSTA LIMA 1951). Os 22 solos paulistas descritos pioneiramente por SETZER (1949) foram representados por números, talvez por julgar impróprias as denominações vigentes, ou por caráter provisório, até que denominações mais definitivas se impusessem.

Todavia, a classificação paulista que se consagrou foi a concebida pela equipe do Instituto Agronômico de Campinas (PAIVA NETTO et al. 1951), com nítida influência do germânico FALLOU (1862). O mapa dos "grandes tipos de solos do Estado de São Paulo" trazia na sua legenda os solos assim denominados: Devoniano, Glacial, Arenito Bauru, Terciário, Massapé, Salmourão, Terra Roxa e Baixadas, ou seja, fortemente influenciados pelo substrato geológico, seguindo Fallou, conforme análise crítica de ESPINDOLA (2014).

As diferentes terras roxas receberam designativos identificatórios: um solo argiloso de rocha básica era Terra Roxa Legítima; com contribuição de materiais arenosos era Terra Roxa Misturada (VERDADE 1951). Descrições de perfis nem sempre atendiam às normas consagradas, como no caso de a, b, c, d para a sequência de horizontes de KÜPPER (1951), que usou, além disso, expressões populares como "estrutura encaroçada" para a Terra Roxa Legítima e a "cor amarelo-marrão" para outros solos.

A forte influência do substrato geológico na denominação dos solos fôra também absorvida por MORAES RÊGO (1945), que assinalava solos eluviais de granitos e gnaisses, solos das serras 
de rochas cristalofilianas não granitizadas e solos eluviais de calcários metamórficos antigos e de rochas anexas. Os primeiros levantamentos de reconhecimento dos solos dos estados federativos do Brasil também reforçaram o substrato como fator de formação.

No Rio de Janeiro começaram a despontar institutos voltados a pesquisas em solos, ecologia e química, como o Instituto de Química criado em 1918, posteriormente Instituto de Química Agrícola - IQA, órgão embrião do Serviço Nacional de Pesquisas Agronômicas - SNEPA, detentor da emblemática Comissão de Solos. O instituto atuava em consonância com a Escola Nacional de Agronomia em Seropédica ( $\mathrm{km} 47$ da rodovia Rio de Janeiro-São Paulo), mais tarde renomeada Universidade Rural, Universidade Federal Rural do Brasil e Universidade Federal Rural do Rio de Janeiro (atual UFFRJ), baluarte no desenvolvimento da ciência do solo brasileira (FARIA 1997).

Um pioneiro mapa de solos em nosso território foi o "Levantamento do mapa de solos da bacia de irrigação do açude público Santo Antônio de Ruças", no Ceará (AMARAL 1946), publicado na Revista Brasileira de Geologia, pois ainda não existia um veículo apropriado de divulgação sobre solos, nem mesmo uma associação de classe.

Na I Reunião Brasileira de Ciência do Solo realizada no Rio de Janeiro, em 1947, foi instituída a Sociedade Brasileira de Ciência do Solo - SBCS. Nesse evento, foram apresentadas pesquisas, publicadas três anos depois, como o estudo agrológico de uma bacia de irrigação na Paraíba (SOUZA MELLO 1950) e o estudo dos solos da Baixada de Sepetiba, RJ (FAGUNDES et al. 1950), ainda sem se explicitar o termo Pedologia.

Na II Reunião Brasileira de Ciência do Solo, realizada em Campinas, em 1949, já se mencionavam os "levantamentos pedológicos" em Estações Experimentais do IAC - Capão Bonito, Monte Alegre e Ribeirão Preto (PAIVA NETTO et al. 1953). Entretanto, nos mapeamentos praticados no restante do país essas denominações continuavam díspares, o que motivou TAVARES (1951) a propor, na III Reunião da SBCS, em Recife, em 1951, a formalização de uma terminologia nacional, substituindo "levantamento agrológico" ou a generalização "estudo sobre solos" (PAVAGEAU 1951).

Entretanto, praticantes do uso e manejo dos solos estavam mais propensos a levantamentos ditos "conservacionistas" (MARQUES et al. 1955). Cursos e treinamentos intensivos eram disponibili- zados para tal finalidade no Centro de Treinamento de Engenharia Rural da Fazenda Ipanema, em Araçoiaba da Serra/Iperó, SP (LIMA 1956), ainda sem uma preocupação diretamente voltada aos ditames de uma Pedologia (horizontes do perfil e classificações taxonômicas).

O "Manual brasileiro para levantamentos conservacionistas", coordenado por MARQUES (1958), foi de longa e profícua vigência, indo além dos princípios da Pedologia, por abordar também características sócio-econômicas e atributos externos dos perfis, configurando-se mais apropriado o emprego do termo "terra" em vez de "solo". Todavia, no capítulo "Classificação pedológica em que se enquadra o solo" (p. 81 a 93), exibe termos que na época eram ainda de raro uso no meio técnico-científico nacional, como "Solos Latossólicos" e "Solos Podzólicos", além de outros consagrados na taxonomia nortamericana vigente.

Tal como em certos países, circunstâncias econômicas e sociais foram determinantes na execução de levantamentos de solos voltados à solução de problemas específicos de urgência, como o controle de erosão e de secas prolongadas. No Brasil, esse processo foi acompanhado de políticas de incentivo à irrigação em áreas produtivas críticas, tal como em Itaguaí, RJ, onde um levantamento ao nível de séries foi desenvolvido pelo antigo Instituto de Ecologia Agrícola (MENDES et al. 1954).

Por sua vez, avanços no ensino do solo propiciaram o surgimento de cursos de agronomia, como em Cruz das Almas (BA), Pelotas (RS), Piracicaba (SP), Lavras (MG) e Seropédica (RJ). Desta última, a antiga Escola Nacional de Agronomia ENA, notáveis pedólogos estrangeiros interagiram com a Comissão de Solos do C.N.E.P.A., como Luís Bramão, Jakob Bennema, Roy W. Simonson e Wim Sombroek. O solo Rubrozém e o primeiro mapa pedológico da América do Sul surgiram com BRAMÃO \& SIMONSON (1956) e BRAMÃO \& LEMOS (1960), respectivamente; nossos Latossolos passaram a ser mundialmente conhecidos com BENNEMA et al. (1959).

Os levantamentos de reconhecimento de solos do Rio de Janeiro e São Paulo (C.N.E.P.A. $1958,1960)$ reforçaram o uso dos novos designativos dos nossos solos, sobretudo os da taxonomia de THORP \& SMITH (1949), embora os norteamericanos já estivessem comprometidos com um novo sistema classificatório a ser implantado, configurando um Comprehensive System (U.S.D.A. 1960), assimilado pelos diversos países. 
No que concerne ao ensino, coube à antiga Escola Superior de Agricultura do Estado de Minas Gerais, em Viçosa, incluir pioneiramente o "Curso de Solos e Adubos" no seu conteúdo programático, segundo ESPINDOLA (2016), graças à providência do russo naturalizado, Aléxis Dorofeeff, notável Professor Catedrático daquela tradicional instituição (DOROFEEFF 1953).

Pedologia, Geografia Agrária e Geoquímica de Superfície foram denominações tangenciais para conteúdos com certa similaridade ao tratar de solos em cursos não exclusivos das Ciências Agrárias; outros denominativos encontrados com frequência em certas disciplinas são: Solos, Propriedade dos Solos, Gênese e Classificação de Solos. Na Agronomia, onde a Pedologia se consagrou inicialmente, essa multiplicidade é encontrada.

\section{CONSIDERAÇÕES FINAIS}

$\mathrm{O}$ resgate bibliográfico atesta a relativa juventude da Pedologia em países da África, América e Oceania, quando confrontada com a dos países europeus que já dispunham de uma caracterização de seus recursos naturais antes do surgimento da Ciência do Solo. No Brasil, assim como nos demais países coloniais, o seu desenvolvimento até meados do século XX contou, na maioria das vezes, com o suporte científico de pesquisadores estrangeiros, até que emergissem seus próprios cientistas. O limite temporal estabelecido para o presente trabalho atesta essa "mescla" de nomes estrangeiros e nacionais na produção científica.

Como deve ter ficado patente, Pedologia e Ciência do Solo muitas vezes se confundem, a despeito de a primeira, stricto sensu, referir-se a um ramo da segunda, mais abrangente. Reforça-se, por isso, que antes da existência da Pedologia, na segunda metade do século XIX, os solos eram estudados sem a sistematização observada nas ciências convencionais, embora de maneira científica. A inclusão de uma taxonomia pedológica, por exemplo, possibilitou correlacionar solos de diferentes domínios morfoclimáticos, o que se configura como indispensável à difusão do conhecimento científico.

O Brasil beneficiou-se tanto dos conhecimentos pioneiros da Ciência do Solo mundial voltada aos solos tropicais, como da Pedologia, que começou a deslanchar, a partir dos anos 1960. Contudo, é preciso valorizar a árdua tarefa anterior, de caracterização do nosso "meio físico", indispensável para esclarecer os processos de formação que determinaram os solos (clima, relevo, geologia, geomorfologia e vegetação), sem deixar de levar em conta a complexidade impressa pelas mudanças climáticas ao longo do tempo geológico, gerando pedogêneses superpostas.

É oportuno justificar a ausência de dados sobre diversos países nesta revisão bibliográfica, muitos deles de forte expressão mundial. À medida que esses trabalhos sejam mais difundidos nos meios de comunicação, ou nas sociedades locais que tratam cientificamente dos seus solos, eles poderão ser acrescentados.

\section{REFERÊNCIAS BIBLIOGRÁFICAS}

Cumpre reforçar que muitas das citações do texto não dispõem de registros bibliográficos completos, dadas as recuadas datas em que foram publicadas, sem o rigor hoje exigido, mesmo com o esforço dispendido pelo ISRIC, FAO e outros órgãos congêneres, que divulgam cópias fotografadas dos documentos originais.

ABRUÑA, F.; SMITH, R.M. 1953. Clay mineral types and related soil properties in Puerto Rico. Soil Science, 75: 441-420.

AB'SÁBER, A.N. 1949. Regiões de circundesnudação pós-cretácea no Planalto Brasileiro. Boletim Paulista de Geografia, 1: 3-21.

ACADEMIA DE CIENCIAS DE CUBA 1961. Mapa genético de suelos, escala 1: 250.000. Instituto de Suelos del Instituto Cubano de Geodesia y Cartografía.

AFANASIEV, J.N. 1927. The classification problem in Russian soil science. Leningrad, Academy of Sciences of URSS (Russian Pedological Investigations, V, p. 1-51).

AGAFONOFF, V. 1929. La pédologie. Révue de Géographie Physique et de Géologie Dynamique, 2: 185-214.

AGASSIZ, J.L.R. 1865. On the drift in Brazil, and on decomposed rocks under the drift. American Journal of Science and Arts, 40: 389-390.

AGUIRRE, A.A. 1940. El suelo y sus propriedades. Revista de la Associación Rural Uruguaya, 67: 31-41. 
ALBAREDA, J.M. 1935. La química física y la ciencia del suelo. Madrid, Sociedad Geográfica Nacional, Serie Ciencia del Suelo, $12 \mathrm{p}$.

ALBAREDA, J.M.; ALEIXANDRE, V.; SANCHEZ CALVO, M.C. 1942. Suelos de orígen silúrico pertenecientes al zona húmeda española. Anales de Edafología y Fisiología Vegetal, $492 \mathrm{p}$.

ALBEAR, F.J. 1941. Estudio geológico de los suelos de la Provincia de La Habana. Revista de la Sociedad Cubana de Ingeniería, 36: 489-500.

ALEXANDRE, F.L. 2007. Literatura e educação na memória de uma cidade: um olhar sobre Thales Castanho de Andrade. Faculdade de Educação, Universidade de São Paulo, São Paulo, Dissertação de Mestrado, 218 p.

ALMEIDA, F.F.M. 1951. Relevo de "cuestas" na bacia sedimentar do Rio Paraná. Boletim Geográfico, 10: 587-593. (Transcrito do Boletim Paulista de Geografia ${ }^{\circ} 3,1949$ ).

ALMEIDA, F.F.M.; BARBOSA, O. 1953. Geologia das quadrículas de Piracicaba e Rio Claro, Estado de São Paulo. Rio de Janeiro, DNPM/ DGM (Boletim 143, 96 p.)

AMARAL, E. 1946. Levantamento do mapa de solos da bacia de irrigação do açude público Santo Antônio de Ruças (Município de Ruças, Estado do Ceará). Revista Brasileira de Geologia, 8: 351-366.

AMARGOS, J. L. 1932. La clasificación de suelos. Revista de Agricultura, Comercio y Trabajo, 13-22.

AMEGHINO, F. 1880. La formación pampeana y estúdios de los terrenos de transporte de la cuenca del Plata. Buenos Aires.

AMUNDSON, R.; YAALON, D.H. 1995. E.W. Hilgard and John Wesley Powell: Efforts for a joint agricultural and geological survey. Soil Science Society of America Journal, 59: 4-13.

ARAÚJO, N.A. 2006. A Escola Agrícola de São Bento das Lages e a institucionalização da agronomia no Brasil (1877-1930). Universidade Estadual de Feira de Santana/
Universidade Federal da Bahia, Feira de Santana/Salvador, Dissertação de Mestrado, $205 \mathrm{p}$.

ARCE PEREIRA, L. 1960. Capacidad agrícola de los suelos. Guia para su clasificación. Servicio Agrícola Interamericano - SAI, División de Ingeniería Agrícola, La Paz, 15 p.

ARENA, A. 1945. La clasificación y cartografía de las tierras. INTA, Buenos Aires, 12 p.

ARRHENIUS, O. 1935. A soil survey of the sugar beet soils in Southern Sweden. In: INTERNATONAL CONGRESS OF SOIL SCIENCE, 3, Oxford, Transactions, 122123.

ASNARES, J. 1945. Apuntes y notas sobre una nomenclatura para los suelos del Uruguay, baseada en la geología. Revista de la Facultad de Agronomía, 40: 67-201.

ASTON, B.C. 1906. Soils. New Zealand Departament Agronomy Annual Report 14, p. 105-108.

ATTERBERG, A. 1912. Die mechanischeund die klassifikation der mineral böden sechwedens. Int. Mitt. Bodenkunde, 2: 312-342.

AUBERT, G. 1941. Les sols de la France d'OutreMer. Paris, Ministère Agriculture. Stn. Lab. Rech. Agron., 114 p.

BAEYENS, J. 1938. Les sols de l'Afrique Central, spécialement du Congo Belge. INEAC, Bruxelles, 375 p.

BAJON, D. 1778. Mémoire pour servir à l'histoire de la Guyane Française. Paris, Grangé.

BAKER, C.L. 1923. The lava field of the Parana Basin, South America. Journal of Geology, 31: 66-79.

BALDWIN, M; KELLOGG, C.E.; THORP, J. 1938. Soil classification. In: Soils and Men a Yearbook of Agriculture 1938, U. S. Dept. Agric., p. 979-1001.

BARBOSA, O. 1959. Quadro provisório das superfícies de erosão e aplainamento no Brasil - 1959. Notícia Geomorfológica, 4: 31-33. 
BARIL, R.W. 1985. Historique de la pédologie, de la classification et de la cartographie des sols au Québec. Les Cahiers d'ACFAS, 37: 3-24.

BARSHAD, I.; ROJAS-CRUZ, L.A. 1950. A pedologic study of a podzol soil profile from the equatorial region of Colombia, South America. Soil Science, 70: 221-236.

BAVER, L.D. 1956. Soil physics. John Wiley \& Sons, New York, 489 p.

BAVER, L.D.; RHOADES, H.F. 1932. Aggregate analysis as an aid in the study of soil structure relationships. Journal of the American Society of Agronomy, 24: 920-930.

BAVEYE, P.; CAMARGO, F.A.O.; POSS, R. 2010. The discipline of Soil Science is not doing too badly under different skies. Soil Science, 175: 313-314.

BEATER, B.E. 1959. Soils of the Sugar Belt. Oxford University Press, Natal North Coast, Cape Town.

BEERS, W.F.J. 1949. Reconnaissance soil survey of the Sorong Area, New Guinee. Soil Survey Institute, Bogor.

BENNEMA, J. 1954. Humuswormen in Nederland Landbouwk. Tijdschr, 66: 375-384.

BENNEMA, J.; LEMOS, R.C.; VETTORI, L. 1959. Latosols in Brazil. In: INTERAFRICAN SOILS CONFERENCE, 3, Dalaba, Transactions, 1: 273-281.

BENNETT, H.H. 1928. The soils of Cuba. Tropical Plant Research Foundation, Washington, $410 \mathrm{p}$.

BENNETT, H.H. 1929. Some aspects of soil erosion as a natural problem. American Soil Survey Association Bulletin, 10: 55-74.

BENNETT, H.H.; ALLISON, R. 1928. The soils of Cuba. Washington, Tropical Plant Research Foundation, $410 \mathrm{p}$.

BESOAIN, M.E. 1958. Mineralogía de las arcillas de algunos suelos volcánicos de Chile. Agricultura Técnica, 18: 110-165.

BIROT, P. 1957. Morphologie de la région de Recife. Bulletin de l'Association de Géographes Français, 263/264: 66-70.
BIRREL, K.S.; FIELDES, M. 1952. The allophan in Volcanic-ash soils of New Zealand. Journal of Soil Science, 3: 156-166.

BLANCK, E. 1930. Handbuch der Bodenlehre. Springer-Verlag, Berlin, $334 \mathrm{p}$.

BLUME, H.P. 2002. Some aspects of the history of German soil science. Journal of Plant Nutrition and Soil Science, 165: 377-381

BOCKHEIM, J.G.: GENNADIYEV, A.N.; HAMMER, R.D.; TANDARICH, J.P. 2005. Historical development of key concepts in pedology. Geoderma, 124: 23-36.

BOLLA, J.J.; LAVENIR, F. 1908. Analysis of soils of Formosa, Argentina. Cron. Agr. Argentina, 2: 67-72.

BONFILS, C.G.; CACAGNO, J.E.; ETCHEVEHERE, P.H.; IPUCHA, AGUERRE, J.; MIACZYNSKI, C.R.O.; TALLARICO, L.A. 1960. Suelos y erosión en la Región Pampeana Semiárida. Instituto de Suelos y Agrotecnía - INTA, Buenos Aires. Publicación 65. Revista de Investigaciones Agrícolas, 8: 321-396.

BORBA, L.R.; COURAT, J.F. 1975. Ensaio cronológico dos precursores da geologia do Brasil. Revista da Escola de Minas, 32: $34-38$.

BOTELHO DA COSTA, J.V.; AZEVEDO, A.L. 1960. Generalized soil map of Angola. In: INTERNATIONAL SOIL SCIENCE CONGRESS, 7, Madison, Transactions, 4: 56-62.

BOULAINE, J. 1983. V.V. Dokouchaev et les débus de la pédologie. Révue d'Histoire des Sciences, 36: 285-306.

BOULAINE, J. 1994. Early soil science and trends in the early literature. In: P. McDonald (ed.). The literature of soil science. Cornell University Press, p. 20-42.

BOULAINE, J. 1997. Histoire abregée de la Science des Sols. Étude et Gestion des Sols, 4: 141-151.

BRAMÃO, L. 1942. A existência do Chernozem em Portugal. In: CONGRESSO NACIONAL 
DE CIÊNCIAS NATURAIS, 1, Lisboa, Actas, 3: 421-426.

BRAMÃO, L.; DUDAL, R. 1958. Tropical soils. In: PACIFIC SCIENCE CONGRESS, 9, Bangkok, 1957, Proceedings, p. 46-50.

BRAMÃO, L.; LEMOS, P. 1960. Soil map of South America. In: INTERNATIONAL CONGRESS OF SOIL SCIENCE, 7, Madison, $10 \mathrm{p}$.

BRAMÃO, L.; SACADURA GARCIA, S.M.; TEIXEIRA, A. 1949. Carta de solos de Portugal. Lisboa, Estação Agronômica Nacional, Direção de Serviços Agrícolas.

BRAMÃO, L.; SIMONSON, R.W. 1956. Rubrozem - A proposed great soil group. In: INTERNATIONAL CONGRESS OF SOIL SCIENCE, 6, Paris, Transactions, 4: 25-29.

BRAMBILA, M. 1960. Los suelos de México. Rome, FAO, World Resources Office, 136 p.

BRANNER, J.C. 1896. Decomposition of rocks in Brazil. Journal of Geology, 4: 529-540.

BRANNER, J.C. 1919. Outlines of the geology of Brazil to accompany the geologic map of Brazil. Bulletin of the Geoogical Society of America, 30: 189-328.

BREWER, R. 1956. A petrographic study of two soils in relation to their origin and classification. Journal of Soil Science, 7: 268-279.

BREWER, R. 1960. The petrographic approach to the study of soils. In: INTERNATIONAL CONGRESS OF SOIL SCIENCE, 27, Madison, Transactions, 1: 1-13.

BREWER, R.; SLEEMAN, J. 1960. Soil structure and fabric: their definition and description. Journal of Soil Science, 11: 172-185.

BRINKMAN, R. 1959. Bodemkartering Albine Zuid. Dienst Bodemkart, Suriname.

BRUNNICH, J.C. 1900. Some Queensland soils. Queensland Agricultural Journal, 6: 403-418.

BRYSSINE, G. 1950. Humidité et possibilité de lessivage des sols au Maroc. In: INTERNATIONAL CONGRESS OF SOIL
SCIENCE, 4, Amsterdam, Transactions, 1: 64-98.

BUCHANAN, F. 1807. Journey from Madras through Mysore, Canara and Malabar. Geological Magazine, 11: 436.

BUENO, M.L.C. 2002. Catálogo da Coleção Varnhagen da Biblioteca do Itamaraty, Rio de Janeiro. Fundação Alexandre de Gusmão FUNAG, Centro de História e Documentação Diplomática - CHDD, Brasília, 593 p.

BURGESS, P.S. 1917. A study of the principal plantation soil types as found on the Island of Hawaii. Hawaii. Hawaii Sugar Planters Station, Agricultural and Chemical Bulletin, 45, $100 \mathrm{p}$.

CABRERA MESTRE, P. 1945. Los suelos de Cuba y la agricultura científica. Revista de la Sociedad Cubana de Ingeniería, 42: 513-528.

CAILlEUX, A.; TRICART, J. 1957. Zones phytogéographiques et morphoclimatiques du Quaternaire au Brésil. Comptes Rendues de la Societé de Biogéogaphie, 293: 7-13.

CALZOLARI, C. 2013. Research in pedology: A historical perspective. An interview to Prof. Fiorenzo Mancini. In: C. Constantini \& C. Dozzi (eds.). The soils of Italy. New York, Springer, p. 1-17.

CAMARGO, F.A.; ALVAREZ, V.H.; BAVEY, P.C. 2010. Brazilian soil science: from its inception to the future, and beyond. Revista Brasileira de Ciência do Solo, 34: 589-59.

CAMARGO, T.; VAGELER, P. 1936. Análise de solos. I. Análise física. Boletim Técnico do Instituto Agronômico do Estado de São Paulo em Campinas, 24: 1-81.

CAMARGO, T.; VAGELER, P. 1937. Probleme der tropischen und subtropischen Bodenkunde. Bodenk. PflErnahr, 4: 137-161.

CAMPBELL, D.A. 1950. Types of soil erosion in New Zealand. In: INTERNATIONAL CONGRESS OF SOIL SCIENCE, 4, Amsterdam, Transactions, p. 196-199.

CAMPOS GIRAL, H. 1946. Valor práctico de los análisis de suelos. Agro, 1: 14-16. 
CARRERAS, G.J. 1929. Los tipos de suelos en el Departamento de Lambayeque, como reconocerlos y tratarlos. Bol. Comp. Admin. Guano, 5: 551-562.

CASANOVA OLIVA, E. 1991. Introducción a la ciencia del suelo. Facultad de Agronomía, Universidad Central de Venezuela, Caracas.

CHARTERS, C.F. 1941. The soils of British Honduras. Port of Spain, Government Printer.

CHENERY, E.M. 1954. Minor elements in Uganda soils. In: CONFÉRENCE INTERAFRICANE DES SOLS, 2, Leopoldville, 91: 1154-1163.

CHEVALIER, A. 1928. Sur l'origine des campos brésiliens et sur le rôle des Imperata dans la substitution des savanes au forêts tropicales. Comptes Rendus de l'Académie des Sciences Paris, 187: 997-998.

CHICAGO UNIVERSITY. 2012. Primeiro Congresso de Ensino Agrícola, São Paulo, 1911. Typographia Brazil de Rotschild \& Cia, 225 p. (Digitalizado em 28 de fevereiro de 2012).

CHOUBERT, B. 1952. Sédimentation actuelle en Guyane Française. In: CONGRÉS GÉOLOGIQUE INTERNATIONAL， 19, Alger, 4: 69.

CHU, L.T.; MA, Y.M.; SUNG, T.C. 1938. The nomenclature of the various horizons of paddy soils. National Geological Survey of China. Special Soils Publication, 4B: 3-15.

C.N.E.P.A.- CENTRO NACIONAL DE ENSINO E PESQUISAS AGRONÔMICAS. 1958. Levantamento de reconhecimento dos solos do Estado do Rio de Janeiro e Distrito Federal. Rio de Janeiro: Comissão de Solos, Ministério da Agricultura, 350 p. (Boletim, 11)

C.N.E.P.A.- CENTRO NACIONAL DE ENSINO E PESQUISAS AGRONÔMICAS. 1960. Levantamento de reconhecimento dos solos do Estado de São Paulo. Rio de Janeiro: Comissão de Solos, Ministério da Agricultura, 634 p. (Boletim, 12)

COFFEY, G.N. 1912. The development of soil survey work in the United States with a brief reference to foreign countries. Proceedings of the American Society of Agronomy 1911, 3: 115-129.

COHEN,A.; VANDEREIJK, J.J. 1953. Klassificatie en ontsaan van savannen in Suriname. Geologie en Mijnbouw, 15: 202-214.

COINTEPAS, J.P.; ROEDERER, P. 1961. Premiers résultats de l'évolution de la suture du sol para irrigation a l'eau salée en Tunisie. Annales Agronomiques, 12: 121-126.

COLMET-DAAGE, F. 1954. Comparaison des sols des terres basses de Guyane Française avec ceux des Guyanes voisines. Institut Français d'Amérique Tropicale, Cayenne, 59 p. (Rapport 15).

COMEL, A. 1937. Guida per le studio practico del terreno e per il suo rilevame. Instituto dele Edizione Accademichenti Geo-Agronomico.

CONSTANTINI, E.A.C.; DAZZI, C. (eds.). 2013. The soils of Italy. Springer, New York, 353 p.

CONSTANZINI, F. 1908. Contribution to the study of Bolognese soils. Ann. Uffic. Prov. Agr. Bologna, 15: 173-179.

CORNELL UNIVERSITY. 2009. Congresso de Ensino Agrícola, São Paulo, 1912. Pocai \& Weiss Publishers (Digitalizado em 20 de outubro de 2009).

COSTA LIMA, J.W. 1951. Levantamento agrogeológico dos solos da Estação Experimental de Curado. In: REUNIÃO BRASILEIRA DE CIÊNCIA DO SOLO, 3 , Recife, Anais, p. 545-570.

COTTON, C.A. 1922. Geomorphology of New Zealand. Part I. Systematic. An introduction to the study of land forms. Wellington, New Zealand Dominium Museum, $442 \mathrm{p}$.

COULTER, J.K.; McWALTER, A.R.; ARNOTT, G.W. 1958. Soil survey reports. III. The transparak swamp, with particular reference to its development for Padi cultivation. Malayan Agricultural Journal, 39: 99-120.

CRAVETTI, A.L. 1904. Soils of the Province of San Luis, Argentina Republic. An. Min. Agr. Argentina, Section Agr. (Agron.), 1: 21-65. 
CRAWLEY, J.J. 1916. Las tierras de Cuba. La Habana, Est. Exp. Agron., 86 p. (Boletín, 28).

DABIN, B. 1951. Contribution à l'étude des sols de delta central Nigérian. Agronomie Tropicale, 6: 606-637.

DANTIN CERECEDA, J. 1917. Sobre las partículas férricas en los suelos áridos de España. Boletin de la Real Sociedad Española de Historia Natural, 17: 245-248.

DARCEL, F.C. 1952. A review of recent investigations on citrus production, with particular reference to the mineral nutrition on the crop. Tropical Agriculture, 29: 27-87.

DARWIN, C. 1838. On the formation of mould. Proceedings of the Geological Society of London, 2: 274-576.

DARWIN, C. 1844. Geological observations on the volcanic island and parts of South America visited during the voyage of H. M. S. BeagleSmith. Elder \& Co., London, v. 7, 176 p.

DARWIN, C. 1881. The formation of vegetable mould throug the action of worms with some observations on their habits. John Murray, London, $326 \mathrm{p}$.

D’AVEZAC-MACAYA, M.A.P. 1857. Considérations géographiques sur l'histoire du Brésil: examen critique d'une nouvelle histoire générale du Brésil. L. Martinet, Paris, 271 p.

DE ANGELIS D’OSSAT, G. 1900. La geologia agrícola de la provincia di Roma. Supp. Boll. Soc. Agr. Ital., 5, 32 p.

DE ANGELIS D'OSSAT, G. 1924. La fase litologica del terreno, fondamento de classificazione. In: CONFÉRENCE INTERNATIONAL DE PÉDOLOGIE, Rome, 1924, Actes, 3: 307-309.

DÉCOURT, P. 1937. Elementos de mineralogia e geologia. Melhoramentos, São Paulo, $3^{\text {a }}$ ed., $672 \mathrm{p}$.

DEFFONTAINES, P. 1935. Regiões e paisagens do Estado de São Paulo. Geografia, 1: 117-169.

DE GASPARIN, A. 1840. Traité d'agriculture. Paris, La Maison Rustique.
DEHÉRAIN, P.P. 1902. Traité de chimie agricole. Masson, Paris, $2^{\grave{e}}$ ed., 969 p.

D'HOORE, J.L. 1954a. L'accumulation des sesquioxydes libres dans les sols tropicaux. Bruxelles, Publ. INEAC, 132 p. (Sér. Scientifique, 62).

D'HOORE, J.L. 1954b. Prospection, cartographie et classification des sols Africains. In: INTERAFRICAN SOILS CONFERENCE, 2, Léopoldville, Proceedings, p. 1177-1187.

D'HOORE, J.L.; FRIPIAT, J.J.; GASTUCHE, M.C. 1954. Les argiles tropicales et leur oxyde de fer de recouvrement. In: INTERNATIONAL CONGRESS OF SOIL SCIENCE, 5, Léopoldville, Transactions, p. 257-260.

DE LEENHEER, L.; D'HOORE, J.L.; SYS, C. 1952. Cartographie et charactérization pédologique de la catena de Yangambi. INEAC, 62 p. (Série Scientifique, 55).

DEL LLANO, M. 1958. Primera clasificación de los suelos de la Colombia Equatorial. In: REUNIÓN INTERAMERICANA DE FITOTECNÍA, FITOPATOLOGÍA, ENTOMOLOGÍA Y EDAFOLOGÍA.

DELVIGNE, J. 1959. La minéralogie des sols congolais en rélation avec la soubassement géologique. Paris, Mémoires ORSTOM 13, 177 p.

DEL VILLAR, E.H. 1927. España en mapa internacional de suelos. Instituto Nacional de Investigaciones y Experiencias Agrícolas y Florestales, Madrid, $27 \mathrm{p}$.

DE MARTONNE, E. 1943. Problemas morfológicos do Brasil tropical atlântico. Revista Brasileira de Geografia, 4: 523- 550.

DEMOLON, A. 1948. Dynamique du sol. Dunod, Paris, $4^{\text {ème }}$ ed., $414 \mathrm{p}$.

DENT, J.M. 1947. Some soils problems of empoldered rice lands in Sierra Leone. Empire Journal of Experimental Agriculture, 15: 206-212.

DERBY, O.A. 1889. Retrospecto histórico dos trabalhos geográficos e geológicos efetuados na Província de São Paulo. Boletim da 
Comissão Geográfica e Geológica da Província de São Paulo, nº 1, 26 p.

DERBY, O.A. 1924. In: A. LAPPARENT. Apêndice. Resumo de geologia, Rio de Janeiro, Garnier. As investigações geológicas no Brasil, p. 312, e Estructura geológica e minerais do Brasil, p. 333-343.

DE SAINT AMAND, L.C. 1822. Des colonies, particulièrement de la Guyane Française. Paris, 246 p.

DE SAUSSURE, T. 1804. Recherches chimiques sur la végetation. Nyon Ed., Paris, 327 p.

DÍAS, V. 1948. Los suelos y la agricultura de la Isla de Pascua. Simiente, 17: 213-219.

DIFFLOTH, P. 1927. Agriculture génerale. Le sol et les labours. 4è ed., Baillère et Fis, Paris, $572 \mathrm{p}$.

DIMMOCK, G.M. 1957. Reconnaissance soil map of Tasmania, Sheet 75 Brighton. CSIRO Austalian Division of Soils, Divisional Repport 2/57.

DIOS CALLE, J.; HUMBERTO PINTO, P.A.J.; BRAEUNER, M. 1957. Informe de los trabajos realizados en reconocimiento de suelos em la República de Guatemala. I.A.I.A.S., Turrialba.

DOBROVOL'SKII, G.V.; ROZHKOV, V.A. 2009. On the first Russian textbooks on pedology. Potchovovedenie, 11: 1404-1407.

DOKUCHAEV, V.V. 1879. Short storical description and critical analysis of the more important soils classification. Trav. Soc. Nat. St. Petersburg, 10: 64-67.

DOKUCHAEV, V.V. 1883. The Russian Chernozem. A report to the Free Economics Society. St. Petersburg.

DOKUCHAEV, V.V. 1890-1891. Notes sur l'étude scientifique du sol en Russie au point de vue de l'agronomie et de la cartographie agricole. Bulletin de la Société Belge de Géologie, de Paléontologie et d'Hidrologie Année 1890, IV: 113-115.

DOKUCHAEV, V.V.; SIBIRTSEV, N.M. 1893. Short scientific review of Professor Dokuchaev's and his profil's collection of soils exposed in Chicago in the year 1893. St Petersburg, Department of Agriculture Ministry of Crown Domains for the World's Columbian Exposition at Chicago.

DOROFEEFF, A. 1953. Curso de Solos e Adubos. Viçosa, Escola Superior de Agricultura do Estado de Minas Gerais, 203 p. (Cadernos mimeografados).

DOYNE, H.C.; GLANVILLE, R.R. 1933. Some swamp rice growing soils of Sierra Leone. Tropical Agriculture, 10: 132-138.

DRESCH, J. 1957. Les problèmes géomorphologiques $\mathrm{du}$ Nord-Est brésilien. Bulletin de l'Association de Géographes Français, 263: 48-60.

DROSDOFF, M. 1959. Suelos del sur del Peru. Lima, Plan. Reg. para el Desarrollo del Sur del Peru, vol. 1, 26 p.

DUCHAUFOUR, P. 1956. Traité de pédologie. École Nationale des Eaux et Forêts, Nancy, 578 p.

DUDAL, R. 1957. La cartographie et la classification des sols en Indonésie. Pedologie, 7: 298-314.

DUTHIE, D.W. 1939. The soils of British Guiana South of the 5th parallel, and of theNorth-West District. Agric. J. Br. Guiana, 10: 194-204.

D'UTRA, G. 1897. Elementos de Agrologia. Fascículo I (Primeira Edição). TypographiaOriente, Santo Amaro, 104 p.

D'UTRA, G. 1899. Analysis of soils of São Paulo, Brazil. Boletim do Instituto Agronômico, 10: 375-396.

EDELMAN, C.H. 1946. Les principaux sols de Java. Revue International de Botanique Appliquée et Agriculture Tropicale, 287-288: 505-512.

ELLIS, J.H. 1932. A field classification of soils for use in soil survey. Scientific Agriculture, 12: $338-345$.

EMERSON, W.W. 1954. The determination of the stability of soil crumbs. Journal of Soil Science, 5: 233-250.

ERHART, H. 1926. Étude agrologique des sols de Madagascar. L'influence de l'origine géologique et des facteurs extérieurs sur la 
formation et la valeur culturale des terres latéritiques de l'Est de Madagascar. Librairie Larose, Paris, 112 p.

ERHART, H. 1935. Traité de pédologie. 1. Pédologie générale. Institut Pédologique, Strasbourg, $260 \mathrm{p}$.

ESPINDOLA, C.R. 1992. Memórias pedológicas - Os primórdios dessa ciência. Boletim Informativo, Sociedade Brasileira de Ciência do Solo, 17: 11-12.

ESPINDOLA, C.R. 2007. História da pedologia: um resgate bibliográfico. In: SIMPÓSIO DE PESQUISA E ENSINO DE CIÊNCIAS DA TERRA, 1, e SIMPÓSIO NACIONAL SOBRE ENSINO DE GEOLOGIA NO BRASIL, 3, Campinas, Fac. de Educação/ Unicamp, CD-ROM, p. 349-352.

ESPINDOLA, C.R. 2008. Retrospectiva crítica sobre a pedologia. - Um repasse bibliográfico. Editora da Unicamp, Campinas, 397 p.

ESPINDOLA, C.R. 2010. História do ensino de solos no Brasil. In: SIMPÓSIO BRASILEIRO DE EDUCAÇÃO EM SOLOS, 5, Curitiba, Resumos Expandidos, p. 2-4.

ESPINDOLA, C.R. 2014. A institucionalização da pedologia como ciência por Friedrich Albert Fallou - O caso brasileiro. Revista do Instituto Geológico, 35: 61-70.

ESPINDOLA, C.R. 2016. A história da Pedologia no Brasil. In: SIMPÓSIO BRASILEIRO DE EDUCAÇÃO EM SOLOS, 8, São Paulo, Conferência. Sociedade Brasileira de Ciência do Solo/Universidade de São Paulo.

ESPINOSA, J. 1958. Estudio detallado de los suelos de Concepción Norte. In: REUNIÓN LATINOAMERICANA DE FITOTECNÍA, 4, Santiago (sem referências adicionais).

FAGUNDES, A.B.I.; VETTORI, C. N.; RAMOS, F. 1950. Contribuição para o estudo dos solos da Baixada de Sepetiba. In: REUNIÃO BRASILEIRA DE CIÊNCIA DO SOLO, 1 , Rio de Janeiro, 1947, Anais, p. 393-526.

FALLOU, F.A. 1853. Die achererden des Königsreichs Sachsen, geognotisch untersucht und kasifiziert. Freiberg. (Solos aráveis da Saxônia, com diagnósticos da geologia e classificação).

FALLOU, F.A. 1857. Anfangsgründe der Bodenkunde. Dresden, G. Schönfeld. (Fundamentos de Ciência do Solo).

FALLOU, F.A. 1862. Pedologie oder allgemeine und besondere Bodenkunde. Dresden: G. Schönfeld's Buchhandlung. (Pedologia ou Ciência do Solo geral e especial).

FAO/UNESCO. 1966. Bibliography on soils and related sciences for Latin America. Rome, World Soil Resources Reports 23, 105 p.

FAO/UNESCO. 1969. Informe al Gobierno de Honduras - Los suelos de Honduras. $\mathrm{n}^{\mathrm{o}}$ AT $2630,88 \mathrm{p}$.

FARIA, L.R. 1997. Uma ilha de competência: a história do Instituto de Química Agrícola na memória de seus cientistas. História, Ciências, Saúde, Manguinhos, III: 51-74.

FARR, C.C.; HOGG, E.G.; PAGE, S.; WILD, L.J.; HILGENDORF, F.W. 1919. On the proposal for a soil survey of New Zealand. Transactions and Proceedings of the Royal Society of New Zealand 1868-1961, vol. 51.

FELLER, C.; BOULAINE, J.; PÉDRO, G. 2001. Indicateurs de fertilité et durabilité des systhèmes de cultive au débout du XIXe siècle. L'approche de Albrecht Taër (17521828). Étude et Gestion des Sols, 8: 33-46.

FELLER, C.; BROWN, G.G.; BLANCHART, E.; DELEPORTE, P.; CHERNYANSKII, S. 2003. Charles Darwin, earthworms and the natural sciences: various lessons from past to future. Agriculture, Ecosystems and Environment, 99: 29-49.

FELLER, C.; BLANCHART, E.; YAALON, D.H. 2006. Some major scientists (Palissy, Buffon, Thaer, Darwin and Müller) have described soil profiles and developed soil survey techniques before 1883. In: B.P. Warkentin (ed.) Footprints in the soil: people and ideas in soil history. Elsevier Science, p. 85-105.

FELLER, C.; BLANCHART, E.; HERBILLON,A.; LEPRUN, J.C.; POSS, R. 2007. L'importance des recherches coloniales, en particulier à Madagascar, dans le développement de la 
pédologie française. Étude et Gestion des Sols, 14: 305-315.

FELLER, C.; AESCHLIMANN, J.P. FROSSARD, E.; LUTZ, V. 2008. Friedrich Albert Fallou (1794-1877) et sa "pedologie" - La preface de l'ouvrage. Étude et Gestion des Sols, 15: 131-137.

FELLER, C.; MARSILY, G.; MOUGIN, C.; PÉRÈS, G.; POSS, R.; WINIARSKI, T. 2016. Le sol - Une merveille sous nos pieds. Belin, Paris, 256 p.

FESCA, M. 1879. Handbuch der tropischen agrikultur I. Leipzig, 172 p.

FIELDES, M.; SWINDALE, L.D. 1954. Chemical weathering of silicates in soil formation. New Zealand Journal of Science and Technology, 36: 140-154.

FIGUEIREDO, F.E.A. 1908. A terra. Apontamentos de geologia agrícola. Livraria Clássica Editora, Lisboa, 708 p.

FLATHE, H.; BENDER, F.; LÜDERS, R. 1960. Resultados de las investigaciones hidrogeológicas, geofísicas y edafológicas en el Chaco Boreal, Paraguay 1959. Asunción, Secretariat for Planning and Development.

FOREMAN, F.W. 1907. Soils of Cambridgeshire. Journal of Agricultural Science, 2: 161-182.

FRANCO, A. 1936. A evolução da sciência do solo. Rodriguésia, 1: 9-19.

FREITAS, R.O. 1951. Ensaio sobre a tectônica moderna no Brasil. São Paulo: FFCL/USP, 120 p. (Boletim 130, Geologia 6).

FRENGUELLI, J. 1955. Loess y limos pampeanos. Facultad de Ciencias Naturales y Museo, Serie Tecnica y Didactica No. 7, La Plata.

FUNAG - FUNDAÇÃO ALEXANDRE GUSMÃO 2002. Centro de História e Documentação Diplomática. FUNAG, CHDD, Brasília, 593 p.

FUNARO, A. 1904. Il manuale di chimica del terreno. Hocpli, Milano.

FUSSEL, K.E. 1951. General soil survey reconnaissance in Costa Rica of potential lands for the production of abaca. IICAAbaca Research Report $\mathrm{n}^{\circ}$. 13, Turrialba, $5 \mathrm{p}$.
FYNN, C.A. 1946. Los factores de formación y la clasificación de los suelos. Montevideo, Ministerio de Ganadería y Agricultura $\mathrm{n}^{\circ}$. 85.

FYNN, C.A.; TOBLER BOTTINI, H.; LÓPEZ TABORDA, O.; DE LEÓN, L. 1959. Características de los grandes grupos de suelos de Uruguay a través de algunas series típicas. In: REUNIÓN ARGENTINA DE LA CIENCIA DEL SUELO, 1, Buenos Aires, Actas, p. 147-148.

GARDNER, G. 1846. Travels in the interior of Brazil, principally through the northern provinces, and the gold and diamonds districts, during the years 1836-1841. Reeve Brothers, London, $562 \mathrm{p}$.

GAUDENZI, N. 1934. Contributo alla conoscenza delle terre rosse emiliane. Ann. Staz. Sperim. Agric. Modena, 3. "Terra rossa of Emile". International Society of Soil Science, 9: 208-210.

GERASIMOV, I.P. 1933. On soil-climatic facies of the USSR. Proc. Dokuchaev Soil Institute, 8: 29-37.

GERASIMOV, I.P.; GLAZOVSKAYA, M.A. 1960. Fundamentals of soil Science and geography. Geografgiz, Moscow, 490 p.

GERBER, H. 1874. Noções geographycas e administrativas da província de Minas Geraes. $2^{\mathrm{a}}$ ed., Typographia Real de Jaenecke e Irmãos, Hannover, 85 p.

GLINKA, K.D. 1916. Schematic soil map of the world, scale 1:80,000,000. Potchovovedenie, 2, St. Petersburg (Original em russo).

GLINKA, K.D. 1927. Dokuchaiev's ideas in the development of pedology and cognate sciences. In: INTERNATIONAL CONGRESS OF SOIL SCIENCE, 1, Washington, Proceedings, p. 116-136.

GLOVER, P.E. 1950. Rain-water in British Somaliland soils. East African Agricultural Journal, 15: 663-700.

GOLDFEDER E CASTRO, P.M. 2012. Minas do Sul: visão corográfica e política regional no século XIX. ICHS/Universidade Federal 
de Ouro Preto, Mariana, Dissertação de Mestrado, $277 \mathrm{p}$.

GOLDICH, S.S.; BERGQUIST, H.R. 1947. Aluminous lateritic soil of the Sierra de Bahoruco area, Dominican Republic. U.S. Geological Survey Bulletin, 953-C: 53-84.

GONG, Z. 1989. Review of Chinese soil classification for the past four decades. Acta Pedologica Sinica, 26: 217-225 (Original em chinês, com resumo em inglês).

GONZÁLEZ, A. 1959. Observations on soils of the watershed of the Atrato River and their chemical analysis. Acta Agronómica, 8: 143-165.

GONZÁLEZ GALLARDO, A. 1949. Introducción al studio de los suelos. México, D.F., 484 p.

GORCEIX, H. 1890. L' État de São Paulo. Comptes Rendus Société Géographes, 409-505.

GORTANI, M. 1913. Terra Rossa, bauxite, laterite. Giornale de Geologia Pratica, 11: 21-39.

GOUROU, P. 1938. Sols et climats dans l'Inde e Indochine. Annales de Géographie, 47: 507-509.

GRANJE, L.I.; GIBBS, H.S. 1948. Soil erosion in New Zealand. Par 1. Southern Half of North Island, v. 2, Soil Bur. 1.

GRANT ARIAS, H.; AVILA SOLÉ, O. 1950. Estudio agrológico de las fincas La Guaria y La Trinidad en el Cantón Central de la Província de Alajuela.

GRANT, C.J. 1962. World soil groups in Hong Kong. In: P. Lumb (ed.) Symposium of Hong Kong soils. Hong Kong, Local Property \& Printing, p. 9-18.

GREVE, M.H.; BREUNING-MADSEN, H. 2005. Soil mapping in Denmark. European Siol Bureau, Research Report ${ }^{\circ} 6$.

GRIMME, C. 1911. Böden-analysen aus DeutschSüdwest Afrika. Arb. Deut. Landw. Ges., 128-135.

GRUNWALD, O.; UZKATEGUI, L. 1940. Breves instrucciones sobre la obtención de muestras de suelos para análisis físico y químico. $E l$ Agricultor Venezolano, 4: 45-49.
GUIMARÃES, D. 1933. Província magmática do Brasil Meridional. Rio de Janeiro: Instituto Geológico e Mineralógico do Brasil, 78 p. (Boletim, 64).

GUISAN, S. 1788. Traité sur les terres noyées de Guyane appelées terres bases, sur leur dessèchement, leur culture et l'explotation de leur productions: avec des réflexions sur la régie des esclaves et autres objets. Imprimerie du Roi, Cayènne, 352 p.

GUTIERREZ CORTÉS, H. 1951. Clasificación de los suelos cafeteros. Chinchina: Instituto Interamericano de Comercio Agropecuario (Boletín Informativo).

HAGENZIEKER, F. 1957. Soil-nitrogen studies at Urambo Tanganyica, East Africa. Plant and Soil, 9: 97-113.

HANSBERRY, R. 1952. Desarrollo reciente de la química agrícola. Turrialba, 2: 92-96.

HARDY, F.; FOLLET-SMITH, R.R. 1931. Studies on tropical soils. II. Some characteristic igneous rock soil profiles in British Guiana, South America. Journal of Agricultural Science, 21: 739-761.

HARDY, F.; SMART, H.P.; RODRIGUEZ, G. 1935. Some soil types of British Honduras. Government Printer, Port of Spain.

HARRASSOWITZ, H. 1930. Boden der tropischen region. Laterit und allitischen Rotlehm. Handbuch der Bodenhehre, 3: 387-536.

HARRISON, J.B. 1910. III. The residual earths of British Guiana termed "laterite". Geological Magazine, 7: 439-452.

HART, M.G.R. 1959. Sulphur oxidation in Tidal Mongrove soils in Sierra Leone. Plant and Soil, 11: 215-236.

HARTEMINK, A.E. 2010. Soil profiles: the more we see, the more we understand. In: WORLD CONGRESS OF SOIL SCIENCE, 19, Brisbane, Australia, Proceedings, p.19-22.

HARTEMINK, A.E.; MCBRATNEY, A.; MINASNY, B. 2008. Trends in Soil Science education: looking beyond the number of students. Journal of Soil and Water Conservation, 63: 76 A-83 A. 
HARTEMINK, A.E.; KRASILNIKOV, P.; BOCKHEIM, J.G. 2013. Soil maps of the world. Geoderma, 207-208: 256-267.

HARTT, C.F. 1885. Contribuições para a ethnologia do valle do Amazonas. Archivos do Museu Nacional, 6, Rio de Janeiro, 174 p.

HAYOT, O. 1881. Matériaux pour l'histoire de la Martinique agricole. Fort de France, Martinique: Imprimerie du Gouvernement.

HENDRICKS, S.B.; FRY, W.H. 1930. The results of X-ray and microscopical examinations of soil colloids. Soil Science, 29: 457-479.

HÈNIN, S. 1948. Essai d'une thèorie de la stabilité de la structure des sols. Plant and Soil, 1: 1667-178.

HÉNIN, S.; GRAS, J.; MONIER, G. 1960. Le profil cultural. Paris, Societé d'Éditions des Ingéniers Agricoles.

HENRY, Y. 1931. Terres rouges et terres noires basaltiques d'Indochine. Impr. d'Extrème Orient, Hanoi, 210 p.

HENRY, E. 1908. Les sols forestiers. BergerLevrault et Cie, Nancy, 392 p.

HERMANN, R. 1836. Über chemische Untersuchungen von Tschernosiomböden. Landw. Jour. Mosk. Landw. Ges., 262 p.

HERMANN, R. 1869. Sem título, citado por GERBER (1874) como publicado no Journal für praktische Chemie, München, v. 1, 72 p.

HILGARD, E.W. 1860. Report on the geology and agriculture of the State of Mississipi. Jackson, E. Banksdale State Printer, Mississipi, 391 p.

HITCHCOCK, E. 1838. Re-examination of the economical geology of Massachussets. Dutton and Wentworth State Printer, Boston, $391 \mathrm{p}$.

HOLLSTEINS, W. 1930. Bodenkarte de Erde, scale 1: 125.000.000. In: E. Blank (ed.). Handbuck der Bodenlehre. v. 3, Berlin, Verlag von Julius Springer, $550 \mathrm{p}$.

HOVEROU, H.N. 1960. Contribution a l'étude des sols du sud Tunisier. Annales Agronomiques, (Série A), 11: 241-308.
HOYOS DE CASTRO, A.; RODRIGUEZ, J. 1956. Genèse du sol dans les régions tropicales humides. In: INTERNATIONAL CONGRESS OF SOIL SCIENCE, 6, Paris, Proceedings, v. E, p. 307.

HOYOS SÁINZ, L. 1908. Las bases de la geología agrícola en España y sus actuales métodos. In: CONGRESO DE SARAGOZA DE LA ASOCIACIÓN ESPAÑOLA PARA EL PROGRESO DE LAS CIENCIAS, Zaragoza, Actas, 297-313.

HUNDESHAGEN, J.C. 1830. Die bodenkunde in Land-u. Forst Wirtschaftlichen Beziehung. Tübingen: Heinrich Laupp.

HWANG, S.; TAI, C.; CHEN, P.; LU, P. 1956. Characteristics of the soils of the Lushan area, Central China. In: CONGRÈS INTERNATIONAL DE LA SCIENCE DU SOL, 6, Paris, vol. A, p. 256.

IICA - INSTITUTO INTERAMERICANO DE CIENCIAS AGRÍCOLAS. 1951. Soil of Los Andes área, Guatemala. Turrialba, Interam. Inst. Agric. Sci. Abaca Res. Report 6, 30 p.

IMPERIAL BUREAU OF SOIL SCIENCE. 1938. What is the use of pedology? Soils and Fertilizers, 1: 3-4.

IMPERIAL BUREAU OF SOIL SCIENCE. 1940. Obituary notice. Soils and Fertilizers, 3: 147-148.

INSTITUTO DE SUELOS Y AGROTECNÍA. 1945. Nuevos símbolos para levantamentos edafológicos. Ministério de Agricultura de la Nación. República Argentina. In: CONFERENCIA INTERAMERICANA DE AGRICULTURA, 3, Caracas, 19 p.

IVES, N.C. 1951. Soil and water runoff studies in a tropical region. Turrialba, 1: 240-244.

JACKSON, M.L. 1958. Soil chemical analysis. Prentice Hall, Englewood Cliffs, 498 p.

JACKSON, M.L.; SHERMAN, G.D. 1953. Chemical weathering of minerals in soils. Advances in Agronomy, 5: 219-318.

JENNY, H. 1941. Factors of soil formation. McGraw Hill, New York, 281 p. 
JENSEN, H. 1944. The Matricula of 1844. Journal for Measurement and Matriculatory Services, 17: 5-23. (Original em língua dinamarquesa)

JENSEN, H.I. 1914. The soils of New South Wales. N.S.W. Department of Agriculture, Sydney, 199 p.

JESUITAS, E.J.; AGLIBUT, A.P.; SANDOVAL, A.R. 1961. Measurement of potencial evapotranspiration as a basis for irrigation crops. Philippines Agriculture, 45: 165-180.

JOACHIM, A.W.R. 1935. Studies in Ceylon soil. II. General characteristics of Ceylon soils, some typical soil groups of the Island, and a tentative scheme of classification. Tropical Agriculturalist, 84: 323-334.

JOACHIM, A.W.R. 1955. The soils of the Ceylon. Tropical Agriculturalist, 111: 161-172.

JOFFE, J.S. 1932. Russian studies on soil profiles. Journal of American Society of Agronomy, 24: 33-57.

JOFFE, J.S. 1936. Pedology. Pedology Publication, New Jersey, 576 p.

JOHNSON, D.L. 1990. Biomantle evolution and the redistribution of earth materials and artifacts. Soil Science, 149: 84-102.

JONGERIUS， A.; SCHELLING， J. 1960. Micromorphology of organic matter formed under the influence of soil organisms, especially soil fauna. In: INTERNATIONAL CONGRESS OF SOIL SCIENCE, 7, Madison, Transactions, 2: 702-710.

JOURNAUX, A.; DEWOLF, Y. 1958. L'étude et cartographie des formations superficielles en Normandie. Caën, Études et Documents pour l'Enseignement Agricole du Premier Degré, 4.

JURITZ, C.F. 1898. Analysis of Malbelbury soils. Agricultural Journal Cape Good Hope, 18: 818-822.

KAMOSHITA, Y. 1940. The soil types of the Tugaru Plain, Aomori Prefecture, Nippon. Journal Agricultural Experiment Station, 3: 401-430.
KAMOSHITA, Y. 1955. General map of soil types in Japan. Journal Agricultural Experiment Station, Tokyo, 25: 253-258.

KANDIAH, S. 1952. Soil surveys for colonization schemes. Paradenya Ceylon, 108: 266-268.

KANNO, I. 1959. Clay minerals of volcanic-ash soils and pumices in Japan. Bull. Toyama Pref. Agricultural Experiment Station, Special Publication n. 1, 105 p.

KARIM, A.; KHAN, D.H. 1955. Soil of Nanakhi, East Pakistan: morphology, textural separates, exchangeable cations. Soil Science, 80: 139146.

KATZER, F. 1903. Grundzüge der geologie des unteren Amazonas Gebietes. M. Weg, Liepzig, 296 p.

KELLEY, W.P. 1912. The origin, composition and properties of the manganiferous soils of Oahu. Hawaii Experiment Station Bulletin, 26: $42-56$

KELLOGG, C.E. 1937. Soil survey manual. USDA, Washington D.C.: Gov. Printing Office, 130 p. (Miscellaneous Publication, 274).

KELLOGG, C.E. 1948. Preliminary suggestions for the classification and nomenclature of great soil groups in tropical and equatorial regions. In: COMMONWEALTH BUREAU OF SOILS, 1, Transactions, p. 78-85.

KIEL, H. 1955. Heavy mineral investigations of samples of Surinam. Geologie Mijnbouw, N.S. 17: 93-103.

KIENER, P. 1954. Contribución al estudio de los suelos de la Guayana Venezolana. Boletín de la Facultad de Ingeniería Florestal, 1: 5-12.

KILROE, J.R. 1907. A description of the soilgeology of Ireland, based upon geological survey maps and records, with notes on climate. Dublin, His Majesty's Stationary Office, $300 \mathrm{p}$.

KING, L.C. 1930. Raised beaches and other features of the southeast coast of the North Island of New Zealand. Transactions of the New Zealand Institute, 61: 498-523. 
KING, L.C. 1942. South African scenary. Oliver \& Boyd, Edinburgh, 308 p.

KING, L.C. 1948. Landscape studies in Southern Africa. Proceedings of the Geological Society of South Africa, 50: 23-55.

KING, L.C. 1956. A geomorfologia do Brasil Oriental. Revista Brasileira de Geomorfologia, 2: 147- 263.

KLINGEBIEL,A.A.; MONTGOMERY, P.H. 1961. Land-capability classification. Washington: Soil Conservation Service, U.S. Gov. Print Office, 21 p. (Handbook 210).

KNECHT, T. 1935. Os minerais e minérios do Estado de São Paulo. São Paulo, Diretoria de Publicidade Agrícola, Secretaria de Agricultura, Indústria e Comércio. Separata do Boletim Agrícola de 1934, 93 p.

KOENINGS, F.F.R. 1950. A "Sawah" profile near Bogor (Java). In: INTERNATIONAL CONGRESS OF SOIL SCIENCE, 4, Amsterdam, Proceedings 1: 297-300.

KONONOVA, M.M.; ALEKSANDROVA, I.V. 1958. The biochemistry of humus and some problems of plant nutrition. Izv. Akad. Nauk SSSR, Ser. Biol. 1, 79 p.

KOTZMANN, L.G. 1935. Genetic and chemical characteristics of Rendzina soils. In: INTERNATIONAL CONGRESS OF SOIL SCIENCE, 3, Oxford, Transactions, p. 296-297.

KOVDA, V.A. 1984. L'apport de V. V. Dokuchaev dans la science et l'agriculture. Science $d u$ Sol, 2: 105-112.

KRUMBEIN, W.C.; PETTIJOHN, F.J. 1938. Manual of sedimentary petrology. Appleton Century Crofts, New York, 549 p.

KRUPENIKOV, I.A. 1992. History of soil science. From its inception to the present. Oxonian Press, Calcuta, New Delhi, 352 p.

KUBIENA, W.L. 1938. Micropedology. Collegiate Press, Ames, $243 \mathrm{p}$.

KUBIENA, W.L. 1952. Claves sistemáticas de suelos. Consejo Superior de Investigaciones Científicas, Madrid, 388 p. (Traducción de A.H. Castro).
KUBIENA, W.L. 1953. The soils of Europe. Illustrated diagnosis and systematics. Consejo Superior de Investigaciones Científicas, Madrid, $317 \mathrm{p}$.

KÜPPER, A. 1951. Umidade equivalente e capacidade máxima de campo em duas áreas: Terra Roxa Misturada e Terra Roxa Legítima. In: REUNIÃO BRASILEIRA DE CIÊNCIA DO SOLO, 3, Recife, Anais.

LACROIX, A. 1913. Les latérites et les produits d'altération qui leur sont associés. Nouvelles Archives du Museum d'Histoire Naturelle, 5: 255-356.

LAGOS, A.M. 1958. Estudio micromorfologico de algunos suelos vulcánicos de Chile. Agricultura Técnica, 18: 166-184.

LAPA, J.I.F. 1875. Chímica agrícola ou estudo analytico dos terrenos, das plantas e dos estrumes. Typografia da Academia Real das Sciências, Lisboa, 508 p.

LAPPARENT, A. 1924. Resumo de geologia. Tradução por B.F. Ramiz Galvão. Garnier Livreiro-Editor, Rio de Janeiro, 351 p.

LAVENIR, P. 1909. Agrology of Argentina. Censo Agropecuário Nacional la Ganadería y la Agricultura em 1908, III: 153-231.

LEBARON, A.; AITKEN, P.; JOHNSON, R.; ELY, A. 1973a. Producción y desarrollo agrícola Latino Americano - Catálogo de instituciones nacionales de investigaciones y lista de investigadores americanos. Utah State University, Logan.

LEBARON, A.; DAINES, S.; AITKEN, P.G. 1973b. Bibliography of Latin American agricultural production and evolution. Agency for International Development, Utah State University, U.S.A., Washington, 509 p.

LENEUF, N. 1959. L'altération des granites calcoalcalins et des granodiorites en Côte d'Ivoire forestière et des sols qui en sont derivés. Impr. Lang Grandemange, Thèse, 212 p.

LEWIS, A.D. 1936. Sand dunes of the Kalahari within the borders of the Union. South African Geographical Journal, 19: 25-57. 
LIEBIG, J. 1840. Die chemie in ihrer Andwendung auf Agrikultur und Physiologie. Vieweg und Söhne, Braunschweig, 352 p. (Química e suas aplicações na agricultura e fisiologia).

LIMA, O.F. 1956. Planejamento conservacionista. Centro de Treinamento de Engenharia Rural, Ministério da Agricultura, Fazenda Ipanema, 13 p. (Mimeo).

LIMA E SILVA, R.; POTSCH, W. 1938. Elementos de mineralogia e geologia. Francisco Alves, São Paulo, $5^{\mathrm{a}}$ ed., 404 p.

LISSON, C.I. 1924. Como se generó el suelo peruano. Geol. Paleontol. y Oceanogr. Sint. Min. Per., 1: 75-110.

LLANO BUENAVENTURA, M. 1952. La renovación del medio como factor importante en la fertilidad de los suelos ecuatoriales. Acta Agronómica, 2: 233-239.

LOEWINSSON-LESSING, F. 1889. La cartographie agronomique dans l'Europe Occidentale et en Russie. Essai critique. Travaux de la Commission Pédologique de la Societé Impériale Économique Libre.

LOGSDAIL, D.E.; WEBBER, L.R. 1959. Effect of frost action on structure of haldimand clay. Canadian Journal of Soil Science, 39: 103-106.

LOREDAY, J. 1957. The soils of the SorellCarlton-Copping area, south-east Tasmania, with special reference to the soil formed on basalt. Melbourne, Commonwealth Scientific and Industrial Research Organization. Soil Publication, $\mathrm{n}^{\circ} 8,74 \mathrm{p}$.

LUCAS, M.D.; FREITAS, F.C. 1958. Ensaios de adubação num solo pardo do Alentejo. (cultura em vasos pequenos). Agronomia Lusitana, 20: 295-309.

LUGO-LOPEZ, M.A. 1951. Functional relations between moisture and several equilibrium points and clay content of tropical soils. Journal of the Agricultural University of Puerto Rico, 35: 66-70.

LUGO-LOPEZ, M.A. 1959. Nature and properties of major soils of Lajas Valley. Bulletin Agricultural Experimental Station Univ. Puerto Rico, 149: 5-80.
LYON, T.L. \& BUCKMAN, H.O. 1922. The nature and properties of soils: a college text of edafology. Macmillan Co, New York, 588 p.

MA, Y. 1956. General principles of geographical soil distribution. In: CONGRÈS INTERNATIONAL DE LA SCIENCE DU SOL, 6, Paris, vol. A, p. 257.

MAACK, R. 1950. Notas preliminares sobre clima, solos e vegetação do Paraná. Boletim Geográfico, 84: 1401-1487. (Apresentado em 1948 na forma de tese, aprovada na II Reunião Brasileira de Ciência do Solo, em Campinas, em 1949).

MACHADO, F. 1945. Gênese de alguns solos dos Açores. Boletim da Comissão Reguladora dos Cereais do Arquipélago dos Açores, 3: 1-8.

MACÍAS, M. 1936. Estudio agrológico de gran visión del proyeto Izmiaquilpán y Tasquillo, Hidalgo. México, Pequeña irrig., vol 1.

MACÍAS VILLADA, M. 1955. La edafologia o ciencia del suelo. Cuadernos de Información Económica, 7: 115-116.

MAIGNIEN, R. 1958. Le cuirassement des sols en Guiné, Afrique Occidentale. Strasbourg, Université de Strasbourg, Mém. Serv. Carte Géol. Alsace-Lorraine n. 16, Thèse Doctorat, $239 \mathrm{p}$.

MANCINI, F. 1960. Carta dei suoli d'Italia alla scala 1, 1000,000 con breve commento. Comitato per la Carta del Suoli d'Italia. Zanichelli Editore, Bologna.

MANZANILLA, P. 1958. El suelo, factores de formación y su desarrollo. Agronômica, 1: 19.

MARBUT, C.F. 1927. The great soil groups of the world and their development by K.D. Glinka. Edward Brothers, Ann Arbor (Translation from German to English).

MARBUT, C.F. 1935. Soils of the United States. U.S. Departament of Agriculture Atlas of American Agriculture, part 3, Advance Sheets, $n^{\circ} 8,98 \mathrm{p}$.

MARIVAULT, M. 1848. Noções elementares de geologia, de physica, de chimica, de botanica, e de physiologia vegetal, applicadas 
à agricultura. Typographia União, Pernambuco, 165 p.

MARQUES, J.Q.A. 1950. Conservação do solo em cafezal. Superintendência dos Serviços do Café, Secretaria da Fazenda, São Paulo, 234 p.

MARQUES, J.Q.A. (coord.). 1958. Manual brasileiro para levantamentos conservacionistas. II aproximação. Escritório Técnico Brasil-Estados Unidos, Rio de Janeiro, 135 p.

MARQUES, J.Q.A.; BERTONI, J.; GROHMANN, F. 1955. Levantamento conservacionista. Levantamento e classificação de terras para fins de conservação do solo. Boletim do Instituto Agronômico, 67: 33 p.

MÁRQUEZ, A. 1958. Clasificación preliminar de los suelos dominados por la presa Peña Blanca, Aguascalientes. Sociedad de Recursos Hídricos, Departamento de Agrología, México.

MARR, A. 2015. Uma história do mundo. Intrínseca, Rio de Janeiro, $1^{\mathrm{a}}$ ed., 592 p.

MARSHALL, C.E.; HASEMAN, J.F. 1942. The quantitative evaluation of soil formation and development by heavy mineral studies. Soil Science Society of America Proceedings, 7: 448-453.

MARTINI, J.A.; LEZCANO, P.N.; BROWN, J.W. 1960. Forest soils of the Darien Province, Panama. Tropical Woods, 112: 28-30.

MASSART, J. 1908. The soils of the coast and alluvial districts of Belgium. Recueil De l'Institut. Botanique. Bruxelles, 7: 303-344.

MATHEUS, E.D.; GUZMÁN, L.E. 1955. The soils and agriculture of the Llanos de Coclé, Panama. Servicio Interamericano de Cooperación Agrícola en Panama - SICAP, 151 p.

MATSUI, T. 1957. The weathering of red soils in Okierabu-Zima Island, southwestern Japan. 1. Mineralogical, chemical and mineralogical characteristics. Journal of Science and Soil, 28: $239-242$.

MATTHEI, A. 1928. Über die genesis der böden von Chile. In: INTERNATIONAL SOIL
SCIENCE CONGRESS, 1, Washington, Proceedings, 4: 536-539.

MATTHEI, A. 1944. El suelo: génesis del suelo, morfologia del suelo. Bol. Comp. Admin. Guano, 20: 353-363.

MAXWELL, W. 1895. Report on soils. Hawaiian Planters' Monthley, 14: 577-593.

MEDINA, L.J. 1951. Aspectos relativos a los suelos tropicales y subtropicales en relación con problemas agrícolas venezolanos. Agro, 6: $40-54$.

MEHRA, O.P.; JACKSON, M.L. 1958. Iron oxide removal from soils and clays by dithionitecitrate system buffered with sodium bicarbonate. In: NATIONAL CONFERENCE IN CLAYS AND CLAY MINERALS, 7, Washington, Proceedings, p. 351-358.

MELA MELA, P. 1954. Tratado de edafología y sus distinctas aplicaciones. Editorial Dossat, Madrid, $582 \mathrm{p}$.

MELLA, A.L. 1958. Estudio micromorfológico de algunos suelos vulcánicos de Chile. Agricultura Tecnica, 18: 166-184.

MELLO, M.J.S. 1816. Novo methodo de fazer o açúcar, ou, reforma geral econômica dos engenhos no Brasil. Bahia: Typographia de Manoel da Silva Serva, 89 p.

MENDES, W.P.; CRUZ LEMOS, O.; LEMOS, R.C.; CARVALHO, I.G.O.; ROZEMBURG, R.J. 1954. Contribuição ao mapeamento em série de solos do município de Itaguaí. Instituto de Ecologia e Experimentação Agrícola, Rio de Janeiro, 53 p.

MILLER, R.B.; FITZPATRICK, M. 1959. Biological and chemical changes following scrub burning on a New Zealand hill soil. 2. Changes in soil pH. New Zealand Journal of Science, 2: 171-181.

MILLOT, G. 1949. Rélations entre la constitution et la genèse des roches sédimentaires argileuses. Bull. Geol. Appl. Prospection et Minière, 2, $352 \mathrm{p}$.

MILLOT, G.; BONIFAS, M. 1955. Transformations isovolumétriques dans les phenomènes de 
latérisation et bauxitisation. Bull. Serv. Carte Geol. Alsace et Lorraine, 8, fasc. 1.

MILNE, G. 1935. Some suggested units of classification and mapping, particularly for east African soils. Soil Research, 4: 183-198.

MINISTERIO DE AGRICULTURA Y CRÌA DE VENEZUELA. 1972. Bibliografía edafológica venezolana. In: CONGRESO LATINOAMERICANO DE LA CIENCIA DEL SUELO, 4, Maracay.

MISSÃO DE PEDOLOGIA DE ANGOLA (MPA). 1959. Carta geral dos solos de Angola. 1. Distrito da Huila. Memórias $n^{\circ}$ 9, Junta de Investigações do Ultramar, Lisboa.

MITSCHERLICH, E.A. 1909. Das gesetz des Minimum und das Gesetz des abnehmenden Bodenstrages. Landw. Jahrbücher 38, 537 p.

MODENESI-GAUTTIERI, M; BARTORELLI, A.; MANTESSO-NETO, V.; CARNEIRO, C.D.R.; LISBOA, M.B.A. (orgs.). 2010. A obra de Aziz Nacib Ab'Sáber. Beca-BALL edições, São Paulo, 588 p.

MOHR, E.C.J. 1909. Laterite and its parent rock. Bulletin. Departament Agriculture Indies Netherlands, 28: 1-12.

MOHR, E.C.J. 1930. Tropical soil forming processes and development of tropical soils. University Philippines Experiment Station, Contribution $n^{\circ} 655,203$ p.

MOHR, E.C.J.; VAN BAREN, F.A. 1954. Tropical Soils. Interscience Publishers, New York, 498 p.

MONASTERIO, E.B. 1958. Mineralogía de las arcillas de algunos suelos vulcánicos de Chile. Agricultura Técnica, 18: 59-77.

MONBEIG, P. 1944. Notas relativas à evolução das paisagens rurais no Estado de São Paulo. Rio de Janeiro: IBGE, p.428-430 (Boletim Geográfico, 16)

MONIZ, A.C. (ed.). 1972. Elementos de pedologia. Polígono/EDUSP, São Paulo, 459 p.

MONIZ, A.C. 1982. A história da pedologia no Brasil. In: M.G Ferri; S. Motoyama (coords.). História das ciências no Brasil. EDUSP, EPU, São Paulo, 3: 743-104.
MONTEIRO LOBATO, J.B.R. 1918. Urupês. Seção de Obras do Estado de São Paulo, São Paulo, $1^{\text {a }}$ ed.

MOORMANN, F.R. 1959. Notes sur les conditions pédologiques de la genèse de la plaine des Joncs. Agr. Library Saigon, 34 p.

MOORMANN, F.R. 1961. Les sols de la République de Viet-Nam. Min. Agric. Saigon.

MOORMANN, F.R.; PANABOKE, C.R. 1961. A new approach to the identification and classification of the most important soil groups of Ceylon. Tropical Agriculturalist, v. $117,65 \mathrm{p}$.

MORAES RÊGO, L.F. 1930. A geologia do petróleo no Estado de São Paulo. Rio de Janeiro: Serv. Geol. Min. Brasil, 105 p. (Boletim 46)

MORAES RÊGO, L.F. 1932. Notas sobre a geomorfologia de São Paulo e sua genesis. Instituto Astronômico e Geophísico de São Paulo, São Paulo, 38 p.

MORAES RÊGO, L.F. 1945. Considerações preliminares sobre a gênese e a distribuição dos solos do Estado de São Paulo. Boletim Geográfico, 27: 351-376. (Transcrito da revista Geografia, São Paulo, Ano I, nº 1, 1935).

MORI, A. 1929. La carta del suolo d'Italia. Bollettino della Società Geografica Italiana, Serie 6, 3: 151-160.

MORTON, J. 1843. The nature and property of soils: their connexion with the geological formation on with their rest. James Ridgway, London.

MOSBECH, J.L. 1922. Some messages about it Elderly söderjysk matrikulsvæsen. Journal for Measurement and Matriculatory Services, 9: 229-262 (Original em língua dinamarquesa).

MOURÃO, H.F.C. 1958. Análise estatística dos ensaios de adubação efetuados nos Postos Experimentais de cultura de sequeiro. Agronomia Lusitana, 20: 249-281.

MUGGLER, C.C.; CAMARGO, F.A.O.; OLIVEIRA, L.B.; FARIAS, G.S.; 2013. Brazilian Soil Science Society: brief history, achievements and challenges for 
the near future. Geophysical Research Abstracts, 15: EGU 2013 - 12570, EGU General Assembly 2013.

MÜLLER, J. 1895. Analysis of colonial soils. Agricultural Journal of Cape Colony, 8: 621-624.

MÜLLER, P.E. 1897. Recherches sur les formes naturelles de l'humus et leur influence sur la végétation et le sol. Buger-Levrault \& Cie, Paris/Nancy, $485 \mathrm{p}$.

MURGOCI, G. 1910. Serie der Terra-Rossa böden (Vorläufige Mitteilung). In: CONFERENCE INTERNATIONALEAGROGÉOLOGIQUE, 2, Stockolm, p. 329-330.

MURO, J.C. 1949. Suelos tropicales del Perú. Agron., 15: 65-72.

NASSAR, N.L. 1974. Bibliografia de solos. Instituto de Pesquisas Agropecuárias do Norte - IPEAN, Embrapa, Belém, 290 p. (Bibliografia $\mathrm{n}^{\mathrm{o}}$ 6)

NEUSTRUEV, S.S. 1927. Genesis of soils. Office of the Academy of the Sciences of the USRR, Russian Pedological Investigations, Leningrad, $97 \mathrm{p}$.

NIKIFOROFF, C.C. 1949. Weathering and soil evolution. Soil Science, 67: 218-230.

NORTHCOTE, K.H. 1954. The place and function of pedology in soil science. Soils and Fertilizers, 17: 305-310.

NORTHCOTE, K.H. 1960. A factual key for recognition of Australian soils. CSIRO, Australian Div. Soils, Melbourne (Divional Report 4/60).

NORTON, E.A. 1939. Land classification as an aid in soil conservation operations in "the classification of land". University Missouri, Agricultural Experimental Station, 334 p. (Bulletin, 421)

NOWACKI, A. 1885. Praktische bodenkunde. Anleitung zur untersuchung, klassifikation des bodens. Verlag von Paul Paeev, Berlin.

NYE, P.H. 1954. Soil-forming processes in the humid tropics. 1. A field study of a catena in the West African Forest. Journal of Soil Science, 5: 7-21.
O ESTADO DE SÃO PAULO. 1911. Congresso de Ensino Agrícola. Edição de 27 de maio de 1911, p. 6.

OGG, W. 1950. El valor del estudio de los suelos en la agricultura. Agricultura venezolana, 15: 18-19.

OLÁZABAL, L. 1857. Suelo, clima, cultivo agrário y forestal de la província de Viscaya. In: Madrid, Memorias de la Real Academía de Ciencias, Catálogo de Publicaciones, Parte $2^{\mathrm{a}}, 50 \mathrm{p}$.

OLIVEIRA, A.I.; LEONARDOS, O.H. 1949. Geologia do Brasil. Ministério de Agricultura, Série Didática $\mathrm{n}^{\circ} 22$, Rio de Janeiro, $2^{\mathrm{a}}$ ed., $813 \mathrm{p}$.

OLIVEIRA, L.B. 1951. A capacidade de troca de bases e o índice de saturação de solos da região seca. In: REUNIÃO BRASILEIRA DE CIÊNCIA DO SOLO, 3, Recife, Anais, p. 137-157.

OLIVEIRA, L.B. 2007. Sociedade Brasileira de Ciência do Solo: um olhar sobre sua história. Ed. do Autor, Recife, 195 p.

OLLIER, C.D. 1959. A two-cycle theory of tropical pedology. Journal of Soil Science, 10: 137-148.

OUDIN, A. 1937. Classification pédologique et cartographie des sols de France. Études actuellement realisées. Compte Rendu Académie d'Agriculture de France, 23: 415-423.

OWEN, G. 1951. A provisional classification of Malayan soils. Journal of Soil Science, 2: $20-42$.

PACHARD, W.E. 1929. Informe preliminar sobre la exploración de las tierras no irrigadas en el proyeto de Mesquital, Hidalgo. México, Secr. de Recursos Hídricos, Depto Agr.

PAIVA NETTO, J.E. 1946. Notas pedológicas dos perfis 467 a 474, relacionados com a cultura cafeeira nos Estados do Rio de Janeiro e Espírito Santo. São Paulo, Boletim da Superintendência do Café no 229.

PAIVA NETTO, J.E.; CATANI, R.A.; KÜPPER, A.; MEDINA, H.P.; VERDADE, F.C.; 
GUTMANS, M.; NASCIMENTO, A.C. 1951. Observações gerais sobre os grandes tipos de solos do Estado de São Paulo. Bragantia, 11: 227-253.

PAIVA NETTO, J.E.; KÜPPER, A.; CATANI, R.A.; MEDINA, H.P. 1953. Estudo pedológico da Estação Experimental de Campinas. In: REUNIÃO BRASILEIRA DE CIÊNCIA DO SOLO, 2, Campinas, 1949, Anais, p. 341-342.

PALLMANN, H. 1933. Über die geschichliche entwicklung der bodenkunde. Berichthaus, Zurich.

PANABOKE, C.R. 1959. A study of some soils in the dry zone of Ceylon. Soil Science, 87: 67-74.

PANTON, W.P. 1957. A soil survey Report No 5. The Federal Experimental Station, Jerangau, Trengganu. Malayan Agricultura Journal, 40: 19-29.

PAPADAKIS, J. 1960. Advances recientes en pedología. In: REUNIÓN ARGENTINA DE LA CIENCIA DEL SUELO, 1, Buenos Aires, 1959. IDIA, INTA, Suplemento 1, p. 135-147.

PARRA, J.M. 1954. Fertilidad de los suelos de la zona cafetera de Saldas. Boletín Informativo, Chinchina, Centro Nacional de Investigaciones de Café.

PASSARGE, S. 1903. Bericht über eine Reise im venezuelanischen Guayana. Z. Ges. Erdkde, Berlin.

PAVAGEAU, M. 1951. Estudo comparativo de alguns solos típicos do Planalto Central Brasileiro. In: REUNIÃO BRASILEIRA DE CIÊNCIA DO SOLO, 3, Recife, Anais, p. 585-636.

PÉDRO, G. 1958. Premiers résultats concernants la réalisation expérimentale d'un processus de latérisation. Comptes Rendu de l'Académie des Sciences, Paris, 247: 1217-1220.

PENDLETON, R.L. 1940. Soil erosion as related to land utilization in the humid tropics. In: PACIFIC SCIENCE CONGRESS, 6, Univ. California, Proceedings, 4: 905-920.
PENDLETON, R.L. 1945. Soils of Nicaragua. Rome, FAO Report.

PENDLETON, R.L. 1947. The formation, development and utilization of the soils of Bangkok Plain. The Siam Society, Natural History Bulletin, 14, Bangkok, Thailand.

PERECIN, M.T.G. 2004. Os passos do saber - A Escola Agrícola Prática Luiz de Queiroz. EDUSP, São Paulo, 390 p.

PETERSON, A.W.; LEWIS, A.S. 1953. Estudio del uso de la tierra en Costa Rica. Posible aplicación del método a otras regiones. IICA, Comunicaciones de Turrialba $\mathrm{n}^{\circ} 30,32 \mathrm{p}$.

PETTERMANN, A. 1899. Analysis of the arable soils of Belgium. Revue Genéralé Agronomique, 8: 49-55.

PISSIS, A. 1842. La position géologique des terrains de la partie australe du Brésil. Mémoire de l'Institut de France, v. 10, 358 p.

POLYNOV, B.B. 1923. Soils and their formation. Mysl Publ. House, Petrograd,172 p.

POLYNOV, B.B. 1937. The cycle of weathering. Thomas Murby and Sons, London, 220 p.

PONS, L.J. 1948. Een gedetaillerde bodemkartering van de gemeeente Batenburg. Stichting voor Bodemkartering, Wageningen, $32 \mathrm{p}$.

PONS, L.J. 1960. De relatieve geschiktheid van grouden voor grassland en voor bouwland. Landbouwkundig Tiydschrift, 72: 683-686.

PRASOLOV, I.I. 1937. On nomenclature and fundamentals of genetic soil classification. Soil Science 8. (Traduzido do russo em BOCKHEIM et al., 2005)

PRESCOTT, J.A. 1930. A tentative soil map of Australia. Journal Council for Scientific and Industrial Research Australia, 3: 123.

PRESCOTT, J.A.; PENDLETON, R.L. 1952. Laterite and lateritic soils. Commonwealth Bur. Soil Sci. Techn. Communication 47, 51 p.

PRINCIPI, P. 1943. I Terreni d'Italia, terreno naturali e terreno agrario, con una grande carta pedológica d'Italia a colori. Società Anonima Editrice Dante Alighieri. 
PRITCHETT, W.L.; QUINTANILLA，R. 1952. Mejoramiento del suelo boliviano. Boletín Experimental 3, $22 \mathrm{p}$.

PUJOL, J.L. 1958. El analysis químico de los suelos y la recomendación de fertilizantes. Universidad de Panamá, Tesis, 134 p.

RAMANN, E. 1902. Das vorkmmen klimatischer bodenzonen in Spanien. Zeitschrift der Gesselschaft für Erdkunde, Berlin, p. 165-168.

RAMANN, E. 1905. Bodenkunde. 2nd edition. Springer, Berlin, $431 \mathrm{p}$.

REASIDE, J.D. 1959. Stability of index mineral in soils with particular reference to quartz, zircon, and garnet. Journal of Sedimentology and Pedology, 29: 493-502.

REBELLO DA SILVA, L.A. 1907. Classificação de solos. Rev Agr. Agron. Portugal, 5: 294301.

RICHTER, D.D.; BABBAR, L.I. 1991. Soil diversity in the tropics. Advances in Ecological Research, 21: 315-389.

RIEKEN, F.F. 1959. Informe al Gobierno del Uruguay sobre conocimiento y clasificación de suelos. Roma: FAO, 75 p. (Informe 1129)

RISLER, E. 1884. Géologie agricole. Tomes I à IV, Berger-Levrault, Paris.

ROBERTS, R.; DIAZ VIAL, C. 1957. Clasificación por Grandes Grupos de los suelos de Chile. Dep. Conservación y Administración de Recursos Agrícolas y Forestales. Santiago de Chile, Ministerio de Agricultura.

ROBERTS, R.C. 1951a. Soils of the Guayana área, Honduras. Turrialba, IICA, Abaca Research Report No. 1, 23 p.

ROBERTS, R.C. 1951b. Soils of the Lean Valley, Honduras. San José, Abaca Research Report.7, $19 \mathrm{p}$.

ROBINSON, G.H.; STRIKER, M.M. 1951. Soils of Margarita-Goschen areas, Limon Province, Costa Rica. San José, IAIAS, Abaca Research Report $\mathrm{n}^{\circ}$ 8, $17 \mathrm{p}$.

ROBINSON, G.S.; JACQUES, W.A. 1958. Root development in some common New Zealand pasture plants. Effect of pure sowings of some grasses and clovers on the structure of a Tokumaru sil loam. New Zealand Jornal of Agricultural Research, 1: 199-216.

ROBINSON, G.W. 1916. Studies on the Paleozoic solis of North Walles. Journal of Agricultural Science, 8: 338-384.

ROBINSON, G.W. 1932. Soils, their origin, constitution and classification. Thomas Murby and Sons, London, 576 p.

ROBINSON, J.B.D.; EVANS, H.R. 1959. Camber bed cultivation on ground-water (vlei) soils. I. Experimental cropo yield. East African Agricultural Journal, 24: 134-191.

RODE, A.A. 1947. The soil-forming processes and soil evolution (Translated from Russian to English by J.F. Joffe in the Israel Program for Scientific Translation, Jerusalem).

RODRIGUES, C.M. 1987. Gênese e evolução da pesquisa agropecuária no Brasil: da instalação da corte portuguesa ao início da República. Cadernos de Difusão de Tecnologia, 4: 205-254.

RODRÍGUEZ IRIARTE, J.C. 1961. Instrucciones para tomar muestras de tierra. Riberalta Divulgación 6, La Paz, Estación Experimental Agrícola de los Trópicos.

ROJAS, W.J. 1959. Los suelos de la Venezuela sumetidos a clasificación. El Agricultor Venezolano, 23: 5-7.

ROJAS CRUZ, L.A. 1952. Suelos de la Sabana de Bogotá. Agricultura Tropical, 8: 31-33.

ROMERO, J.P.; ROMERO, C.A.P. 2009. Pioneiros agrícolas: publicações e fatos significativos na agricultura e agronomia. Ceres, São Paulo, 263 p.

ROSSI, R. 1953. Primer mapa de suelos del Perú. Lima, Of. Téc. Agric., S.A.

ROTHE, C. 1844. Report on it in the year 1844, for the Kingdom introduced new indebtednessbeing and history. Copenhagen.

ROY, B.B.; DAS, S.C. 1952. Electrochemical properties of hydrogen clays from Indian black cotton soil. Soil Science, 74: 351-358. 
RUELLAN, F. 1943. A região meridional de Minas Gerais e a evolução do vale do Paraíba. Boletim Geográfico, 1: 95- 102.

RUELLAN, F. 1950. Geomorfologia geral. Boletim Geográfico, 84: 1522-1534.

RUHE, R.V.; DANIELS, R.B. 1958. Soils, paleosols and soil nomenclature. Soil Science Society of America Journal, 22: 66-69.

RUHNKE, G.N. 1926. The soil survey of southern Ontario. Scientific Agriculture, 7: 117-124.

SAINT-HILAIRE, A. 1830. Voyage dans l'intérieur du Brésil. Tome 2 - Voyage dans les Provinces de Rio de Janeiro et de Minas Gerais. Grimbert et Dorez, Paris, 470 p.

SANCHEZ CALVO, M. 1958. El Braulehm y las tendencias de alteración en las Canarias Occidentales. Anales de Edafología y Fisiología Vegetal, 18: 407-502.

SANDS, F.B. 1954. A study of the cacao and cofee soils of Costa Rica. Cornell University, San José, PhD Dissertation, 153 p.

SAUNDERS, W.N.H.; WILLIAMS, E.G. 1955. Observation on determination of total organic phosphorus in soil. Journal of Soil Science, 6: 254-267.

SCHAEFER, C.E.G.R.; SÁ e MELO MARQUES, A.F.; CAMPOS, J.C.F. 1997. Origens da pedologia do Brasil. Resenha histórica. Geonomos, 5: 1-15.

SCHAUFELBERGER, P. 1944. Apuntes geológicos y pedológicos de la zona cafetera de Colombia. Manizales, Centro Nacional de Café. Boletín Informativo, 1: 288.

SCHAUFELBERGER, P. 1955. Um sistema para la clasificación de los suelos de Colombia. Chinchiná, Cenicafé, Boletín Informativo, 6: 83-96.

SCHOLS, H.; COHEN, A. 1953. De ontwikkeling van geologische kaart van Suriname. Geologie en Mijnbouw, Nw. Serie, 15: 142-181.

SCHWERTMANN, V. 1959. Die fraktionierte extraction der frein. Eisenoxy de in boden. Ihre, mineralogishen formen und-ihre. Entstste-bunsweisen. Düng Bodenk., S. Ptlanzenernähr. 84: 194-204.
SÉGALEN, P. 1956. Étude des sols derivés de roches volcaniques basiques à Madagascar. Mémoires IRSM, série D, tome VIII, Thèse, $240 \mathrm{p}$.

SEKI, T. 1930. On a soil map of Japan presented in an international soil science conference. Japanese Journal of Soil Science and Plant Nutrition, 4: 68-77. (Original in Japanese with English summary).

SEKI, T. 1934. On the sialliic and allitic soils. Japanese Journal of Soil Science and Plant Nutrition, 8: 245-256. (Original in Japanese with English summary).

SELVARADJOU, S.; MONTARANELLA, L.; SPAARGAREN, O.; DENT, D.; FILIPPI, N.; REUTER, H.I. 2005. European digital archive of soil maps (EuDasm) - Metadata of the soil maps of Latin America and Caribbean Islands. EUR 21821 EN. Luxembourg: Office of the Official Publications of the European Communities.

SESTINI, F. 1899. Il terreno agrario, sua origine constituzione e proprietà. Nuova Enciclopedia Agraria Italian, Torino.

SETZER, J. 1941. As características dos principais tipos de solos do Estado de São Paulo. Bragantia, 1: 255-359.

SETZER, J. 1945. Noções gerais de pedologia. Boletim Geográfico, 24: 1904-1922.

SETZER, J. 1949. Os solos do Estado de São Paulo. Rio de Janeiro, IBGE, Série A No 6. 387 p.

SIBIRTSEV, N.M. 1895. Genetische bodenklassification. Zap. Novo-Alexander Agr. Inst., 1:1-23.

SIBIRTSEV, N.M. 1897. Étude des sols de la Russie. In: CONGRÈS GÉOLOGIQUE INTERNATIONAL, 7, St. Petersbourg, Comptes Rendus, p. 73-125.

SILVA, A.A. 1959. Estudo da umidade em famílias de solos: a porcentagem a $\mathrm{p} 4,2$ quando relacionada à porcentagem $\mathrm{p} 2,7$. Agronomia Lusitana, 21: 207-212.

SILVA, J.R. 1926. Curso de Química Agrícola. Lisboa, Imprensa Nacional, $632 \mathrm{p}$. 
SILVA TEIXEIRA, A.J. 1947. Glossário de Pedologia. Revista Agronomia, 35: 95-127.

SIMMONS, C.S. 1953. Geography of the soils of Guatemala. Instituto Agropecuario Nacional, Min. Agric. Mimeo, Guatemala.

SIMMONS, C.S. 1959. Dark clay soils of Honduras. Rome, FAO, Soil Resources Office.

SIMONSON, C.H. 1958. Reconnaissance soil survey on the coastal plain of British Guiana. University of Maryland, Washington, 608 p.

SIMONSON, R.W. 1959. Modern concepts on soil genesis. Soil Science Society America Proceedings, 23: 152-156.

SMITH, F.G. 1953. Historical development of inclusion thermometry. University Toronto Press, $149 \mathrm{p}$.

SMITH, F.G.; LITTLE, W.M. 1959. Filling temperatures of $\mathrm{H}_{2} \mathrm{O}-\mathrm{CO}_{2}$ fluvial inclusions of their significance in geothermometry. Canadian Mineralogist, 6: 380-388.

SOCIETY OF AGRICULTURE - JAPAN 1926. Report on investigations of soil classification, nomenclature, soil survey and soil mapping. Tokyo.

SOKOLOVSKY, A.N. 1935. The new map of UKR. S.S.R. (Ukraine), 1: 1,000,000. In: INTERNATIONAL CONGRESS OF SOIL SCIENCE, 3, Oxford, Transactions, p. 274.

SOUZA MELLO, F.E.S. 1950. Estudo agrológico da bacia de irrigação do açude público "São Gonçalo", na Paraíba. In: REUNIÃO BRASILEIRA DE CIÊNCIA DO SOLO, 1 , Rio de Janeiro, 1947, Anais, p. 288-389.

SPEIGHT, R.; WILD, L.J. 1918. River terraces in New Zealand. New Zealand Journal of Science and Technology, 140: 145-152.

SPIX, J.B.; MARTIUS, C.F.P. 1823. Viagem pelo Brasil (1817-1820). Instituto Histórico e Geográfico Brasileiro. Melhoramentos, São Paulo, $3^{\mathrm{a}}$ ed. (Tradução de L. F. Lchmeyer).

SPRENGEL, C. 1837. Die bodenkunde oder die Lehre vom boden nebst einer vollstaendigen anleitung zur chemischen analyse der Ackererden. Leipzig.
STEINER, R. 1924. Agriculture. A course of eight lectures. Byodynamic Agriculture Association, London.

STEPHENS, C.G. 1941. The soils of Tasmania. Melbourne: CSIRO (Bulletin, 139).

STEPHENS, C.G. 1946. Pedogenesis following the dissection of lateritic regions in southern Australia. Melbourne: CSIRO Australia, 20 p. (Bulletin, 206)

STOBBE, P.C.; WRIGHT, J.R. 1959. Modern concepts of the genesis of Podzols. Soil Science Society of America Proceedings, 23: 161-164.

STOOPS, G. 2009. Evaluation of Kubiëna's contribution to micropedology. At the occasion of the seventieth anniversary of his book "Micropedology". Eurasian Soil Science, 42: 693-698.

STREMME, H. 1917. Profile tropischen böden. Geologische Rundschau, 4: 389-393.

STREMME, H. 1928. Olgolna mapa gleb Europy. Intern. Soc. Soil Science, Warszawa.

STRIKER, M.M. 1952. Soil and land investigations in Panama. Washington, Archives of Foreign Agricultural Relations Office, Departament of Agriculture.

SUDO, T. 1951. Minerals from pumiceous tuff in Japan. Science, 113: 266-267.

SWINDALE, L.D. 1955. Mineralogy and genesis of some rhyolite derived soils of New Zealand. University Wisconsin, Madison, $\mathrm{Ph}$ D Thesis, $190 \mathrm{p}$.

SWINDALE, L.D.; JACKSON, M.L. 1956. Genetic processes in some residual podzolised soils of New Zealand. In: INTERNATIONAL CONGRESS OF SOIL SCIENCE, 6, Paris, Transactions, 5: 233-239.

SYS, C. 1955. The importance of the termites in the formation of latosols. Sols Africains, 3: 392-395.

SYS, C. 1960. La carte des sols du Congo Belge et du Rwanda-Urundi. Pédologie, 10: 48-122.

TAMURA, T.; JACKSON, M.L.; SHERMAN, G.D.; 1955. Mineral content of Low Humic, 
Humic and Hydrol Humic Latosols of Hawaii. Soil Science Society of America Proceedings, 17: 343-346.

TANDARICH,J.P.;DARMODY,R.G.;FOLLMER, L.R.; JOHNSON, D.L. 2002. Historical development of soil and weathering profile concepts from Europe to the Unieted Stares of America. Soil Science Society of America Journal, 66: 335-346.

TAVARES, F.D. 1951. Projeto de classificação de solos do Brasil. In: REUNIÃO BRASILEIRA DE CIÊNCIA DO SOLO, 3, Recife, Anais, p. 643-648.

TAVERNIER, R.; MARÉCHAL, R. 1957. Les sols à fragipan dans la région condrusienne. Pédologie, 7: 199-203.

TAYLOR, B.W. 1959. Ecological land clasification in Nicaragua No 4: Land potential on the Leon-Chinandega area. FAO, World Soil Resources Office, 98 p.

TAYLOR, N.H.; FOX, J.E. 1956. The soil pattern of New Zealand. New Zealand Soil Bureau Public. 113, 17 p.

TERUGGI, M.E.; ETCHICHURI, M.; REMIRO, J. 1958. Estudio sedimentológico de los terrenos de las barrancas de la zona de Mar del Plata-Miramar. Revista Museo Argentino de Ciencias Naturales, Geología 4, 107-250.

THAËR, A. 1811. Principes raisonées d'agriculture. 4 tomes. Paris, Prechoud Ed., Paris, 372 p. (Traduit d'allemand par J.E.V.B. Crud).

THORP, J.; SMITH, G.D. 1949. High categories of soil classification - Order, Suborder and Great Soil Groups. Soil Science, 67: 117-126.

TIOBURY, G.E.; CALTON, W.E. 1950. The use of microplots in a reconnaissance survey of nutrient status of the soil of Zanzibar Island. East African Agricultural Journal, 15: 108115.

TIRADO SULSONA, P. 1959. Soils of Paraguay. In: E.B. Ekel-Geology and mineral resources of Paraguay: a reconnaissance. Washington, U.S. Departament Interior, Geolological Survey 101 p. (Paper 327).
TIRADO SULSONA, P.; HAMMON, J.B.; RAMÍREZ, J.R. 1954. Clasificación preliminar de los suelos y terras del Paraguay. Asunción, Min. Agric. I Ganad. / Inst. Asuntos Inter-Amer. Serv. Téc. Interamer. Coop. Agric., 165 p. (Boletín, 119).

TOMLINSON, T.E. 1957. Seasonal variation on the surfasse $\mathrm{pH}$ value of some rice soils from Sierra Leone. Tropical Agriculture, 34: $287-$ 294.

TRICART, J. 1959. Informações para a interpretação paleogeográfica dos cascalheiros. Notícia Geomorfológica, 4: 1-11.

TYURIN, I.V. 1937. Organic matter os soils and its role in the soil formation and fertility. Selchozgiz, Moscow, 275 p.

U.S.D.A. 1960. Soil classification - A comprehensive system. $7^{\text {th }}$ Aproximation. Washington, Soil Survey Staff, Soil Conservation Service, 265 p.

VAGELER, P. 1909. Bodenkunde. Leipzig: Sammlung Göschen Bd 455, 114 p. Soil Science Collection Goschen n ${ }^{\circ} 455$.

VAGELER, P. 1930. Grundis der tropischen und subtropischen Bodenkunde. Verlagsgesellschaft fur Ackerbau, Berlin, $216 \mathrm{p}$.

VAGELER, P. 1933. An introduction to tropical soils. Mac Millan, London, 240 p. (Translated by H. Greene)

VAGELER, P. 1953. Princípios e métodos modernos do levantamento agrogeológico global em áreas grandes virgens. In: REUNIÃO BRASILEIRA DE CIÊNCIA DO SOLO, 4, Campinas, Anais, p. 275-283.

VALENCIA, R.F.J. 1960. Morfología, clasificación y uso de los suelos sonsocuite de Nicaragua. Managua, Ministerio de Agricultura y Ganaderí., Nuestra Tierra, 41: 5-16.

VAN BAREN, H.; HARTEMINK, A.E.; TINKEN, P.B. 2000. 75 years The International Society of Soil Science. Geoderma, 96: 1-18.

VAN BEMMELEN, J.M. 1886. Contribution to the knowledge of the alluvial soils in the Netherlands. Kon. Akad. v. Wetenschappen, Amsterdam. 
VAN DER EYJK, J.J. 1957. Reconnaissance soil survey in northern Surinam. Wageningen, Thesis.

VAN DER MERWE, C.R. 1924. On the formation of soil from diabase in the Central Transvaal. Soils African Journal of Science, 21: 235-242.

VAN DER MERWE, C.R. 1935. Laterites and lateritic red earths in the Union of South Africa. $I n$ : INTERNATIONAL CONGRESS OF SOIL SCIENCE, 3, Oxford, Transactions, 1: 297-300.

VAN DER MERWE, C.R. 1940. Soil groups and subgroups of South Africa. Pretoria, Government Printer, Department of Agriculture \& Forestry - Divison of Chemical Services, $\mathrm{n}^{\circ} 165$.

VAN DER VOORT, M. 1950. The lateritic soils of Indonesia.In: INTERNATIONAL SOIL CONGRESS OF SOIL SCIENCE, 4, Amsterdam, Transactions, 1: 227-281.

VAN HEUVELEN, B.J.; JONGERIUS, A.J.; PONS, L.J. 1960. Soil formation in organic soils. In: INTERNATIONAL CONGRESS OF SOIL SCIENCE, 7, Madison, Transactions, 4: 205-211.

VAN SCHUYLENBORGH, J. 1957. Investigations on the classification and genesis of soils derived from andesitic tuffs under humid tropical conditions. Netherlands Journal of Agricultural Science, 5: 195-210.

VAN WAMBEKE,A. 1959. Le rapport limon/argile, mesure approximative du stade d'altération des matériaux originels des sols tropicaux. In: CONFÉRENCE INTERNATIONALE DES SOLS, 3, Dalaba, Comptes Rendus, 1: 161-167.

VAN WAMBEKE, A. 1993. Early approaches to the study of soils of tropical regions. Pédologie, 43: 41-47.

VEALE, P.T. 1953. Characteristics of certain soils in the Dominican Republic. Soil Science Society America Proceedings, 17: 391-395.

VEGA, J.; ROJAS CRUZ, L.A. 1951. Série de suelos de "La Cabrera" y su fertilidad. Agricultura Tropical, 7: 51-54.
VENKATARAMIAH, P. 1934. Reportor on the soil survey of the Tungabhadra Project. Govern. Press, Madras, 106 p.

VERDADE, F.C. 1951. Estudo da variabilidade dos nitratos num solo tipo Terra Roxa Misturada. In: REUNIÃO BRASILEIRA DE CIÊNCIA DO SOLO, 3, Recife, Anais, p. 129-158.

VERHOOG, J.M. 1950. Soil research on Suriname. In: INTERNATIONAL CONGRESS OF SOIL SCIENCE, 4, Amsterdam, Transactions, p. 28-30.

VILENSKI, G.D. 1924. Die Salzböden und ihre Entschung. Zusamensetzung und Melioration. Moscau (Tradução em alemão). Schematic soil map of Russia and the world. In: G.D. Vilenski. Principal soil types of the world. Georgia, Tiflis (Tradução em inglês).

VINASSA DE REGNY, P. 1904a. Nozioni di geologia agraria. Pisa, E. Spoerri Edizioni, 312 p. e Geol. Zentbl., 7: 54-55.

VINASSA DE REGNY, P. 1904b. Sull' origine dela "terra rossa". Bolletino della Società Geologica Italiana, 23, 158 p.

VON ESCHWEGE, W.L. 1841. Pluto Brasiliensis. Nacional, São Paulo, 2 vols.

VON GIESECKE, F. 1930. Tropische und subtropischehumusundBleicherdebildungen. In: E. Blank. Handbuch der Bodenlehre. Berlin, Springer-Verlag, p. 184-224.

WAEGEMANS, G. 1948. Latérisation et latérites. Centre Col. Doc. et Coord. Cong, Rech. Chim., Bruxelles, 12 p.

WAITZ, P. 1943. Los suelos de México, y las possibilidades de futuros desarrollos agrícolas. FAO/UNESCO, World Soil Resources Reports 23.

WALTHER, K. 1940. Nota sobre algunos tipos de suelos sulamericanos. Contribuciones al estúdio pedológico del Uruguay y Argentina. Boletín de la Academia Nacional de Ciencias, 35: 109.

WASHBURNE, C.H. 1930. Petroleum geology of the State of São Paulo - Brazil. Comissão Geográfica e Geológica do Estado de São Paulo, São Paulo, 282 p. 
WENTWORTH, C.K. 1922. A scale of grade and class terms for clastics sediments. Journal of Geology, 30: 377-392.

WEST, Q.M. 1954. Estudio general del uso de la tierra del área demonstrativa de Roldanillo, Departamiento del Valle del Cuenca, Colombia. Lima, Instituto Interamericano de Ciencias Agrícolas - IICA - Zona Andina, 19 p.

WESTIN, F.C.; AVILAN, J.; BUSTAMANTE, A.1960. Mapa de los Grandes Grupos de suelos de Venezuela. Centro de Investigaciones Agronómicas, Maracay, 3 p.

WHITNEY, M. 1924. The future of the soil survey in our National Agricultural Policy. Journal of the American Society of Agronomy, 16: 409-412.

WIEGNER, G. 1924. Boden und bodenbildung. T. Steinkopff, Leipzig.

WIEGNER, G. 1935. Ionemuntausch und struktur. In: INTERNATIONAL CONGRESS OF SOIL SCIENCE, 3, Oxford, Transactions, p. 5-28.

WILCOX, E.V. 1910. Soils of the Hawaiian Islands. Hawaii Sta. Report, p. 11-12.

WILD, L.J. 1919. Soils and manieres in New Zealand. Auckland Institute and Museums, $134 \mathrm{p}$.
WILDE, S.A. 1963. Pioneers of soil science - A British view. Soil Science, 97: 258-359.

WILNER, J. 1955. The effect of low temperature on available soil moisture during winters on the Canada prairies. Agronomy Journal, 47: 411-413.

WOHLTMANN, F. 1892. Handbuch der tropischen agrikultur I. Leipzig, 172 p.

YAALON, D.H. 2008. Classification: historical developments. Encyclopedia of Soil Science, 1: 1-3.

YAMAZAKI, K. 1960. Studies on the pedogenetic classification of paddy soils in Japan. Bull. Toyama Pref. Agric. Expt. Sta., Special Publ. $\mathrm{n}^{\mathrm{o}} 1,105 \mathrm{p}$.

YARILOV, A.A. 1910. Carl Linnaeus and soil science. Potchovovedenie n 3.

YARILOV, A.A. 1904. Francis Albert Fallou - the founder of Soil Science. Potchovovedenie n. 2.

ZAKHAROV, S.A. 1927. Achievements of Russian Science in morphology of soils. Russian pedological investigations. II. Publishing Office of the Academy of Sciences of the URSS, Leningrad.

ZONNEVELD, J.I.S. 1952. Watervallen in Surinam. Tijdschrift van het Aardrijkskundig Genootschap, 69: 499-507.

\section{Endereço do autor:}

Carlos Roberto Espindola - Faculdade de Engenharia Agrícola e Instituto de Geociências, Universidade Estadual de Campinas (UNICAMP), Cidade Universitária Zeferino Vaz, Distrito de Barão Geraldo, CEP 13.083-875, Campinas, SP, Brasil.E-mail: crobertoespindola@gmail.com

Artigo submetido em 10 de maio de 2018, aceito em 23 de agosto de 2018. 